\title{
First Results of Undersea Muography with the Tokyo-Bay Seafloor Hyper-Kilometric Submarine Deep Detector MAGMA-HKMSDD Collaboration
}

Hiroyuki K.M. Tanaka ( $\nabla$ ht@eri.u-tokyo.ac.jp )

University of Tokyo

Cristiano Bozza

The University of Salerno

Rosa Coniglione

Istituto Nazionale di Fisica Nucleare - Laboratori Nazionali del Sud

Jon Gluyas

Durham University

Sara Steigerwald

The International Virtual Muography Institute (Global)

Marko Holma

University of Oulu

Pasi Kuusiniemi

Arctic Planetary Science Institute

Giovanni Leone

The University of Atacama

Hirohisa Mori

University of Tokyo

Jun Matsushima

University of Tokyo

Sean Paling

Boulby Underground Laboratory

Domenico Lo Presti

The University of Catania

Tadahiro Kin

Kyushu University

Osamu Kamoshida

NEC Corporation

Masaatsu Aichi

University of Tokyo

László Oláh 
University of Tokyo

\section{Kenji Sumiya}

Kansai University

\section{Lee F. Thompson}

University of Sheffield

\section{Yusuke Yokota}

University of Tokyo

\section{Dezső Varga}

Wigner Research Centre for Physics

\section{Naoto Hayashi}

University of Tokyo

\section{Yukihiro Nomura}

University of Tokyo

Yasuhiro Kato

University of Tokyo

Hideaki Miyamoto

University of Tokyo

Kenji Shimazoe

University of Tokyo

\section{Hiroyuki Takahashi}

University of Tokyo

Masaki Satoh

University of Tokyo

\section{Research Article}

Keywords: TGSs, Tidal measurements, topography and bathymetry, TS-HKMSDD, Hyper-Kilometric

Posted Date: May 26th, 2021

DOl: https://doi.org/10.21203/rs.3.rs-541987/v1

License: (9) This work is licensed under a Creative Commons Attribution 4.0 International License. Read Full License 
1 First Results of Undersea Muography with the Tokyo-Bay

2 Seafloor Hyper-Kilometric Submarine Deep Detector

3

4 Hiroyuki K.M. Tanaka*1,18, Masaatsu Aichi ${ }^{1}$, Cristiano Bozza ${ }^{2,18}$, Rosa Coniglione ${ }^{3}$, Jon

5 Gluyas $^{4,15,18}$, Naoto Hayashi ${ }^{1}$, Marko Holma ${ }^{5,6,7,18}$, Osamu Kamoshida ${ }^{8,18}$, Yasuhiro

6 Kato $^{1}$, Tadahiro Kin ${ }^{9,18}$, Pasi Kuusiniemi ${ }^{6,718}$, Giovanni Leone ${ }^{10,18}$, Domenico Lo

7 Presti $^{11,12,18}$, Jun Matsushima ${ }^{1,18}$, Hideaki Miyamoto ${ }^{1}$, Hirohisa Mori ${ }^{1,18}$, Yukihiro

8 Nomura $^{1}$, László Oláh ${ }^{1,18}$, Sara Steigerwald ${ }^{18}$, Kenji Shimazoe ${ }^{1}$, Kenji Sumiya ${ }^{13,18}$,

9 Hiroyuki Takahashi ${ }^{1}$, Lee F. Thompson ${ }^{14,15,18}$, Yusuke Yokota ${ }^{1}$, Sean Paling ${ }^{16}$, Masaki

10 Satoh $^{1}$, Dezső Varga ${ }^{17,18}$ on behalf of MAGMA-HKMSDD Collaboration.

11

12

13 1. University of Tokyo, Japan

14 2. The University of Salerno, Italy

15 3. Istituto Nazionale di Fisica Nucleare - Laboratori Nazionali del Sud, Italy

16 4. Durham University, UK

17 5. Kerttu Saalasti Institute, University of Oulu, Finland

18 6. Muon Solutions Oy Ltd, Finland

19 7. Arctic Planetary Science Institute, Finland

20 8. NEC Corporation, Japan

21 9. Kyushu University, Japan

22 10. The University of Atacama, Chile

23 11. The University of Catania, Catania, Italy

24 12. Istituto Nazionale di Fisica Nucleare, Catania, Italy

25 13. Kansai University, Osaka, Japan

26 14. The University of Sheffield, UK

27 15. Geoptic Ltd., UK

28 16. Boulby Underground Laboratory, UK

29 17. Wigner Research Centre for Physics, Hungary

30 18. International Virtual Muography Institute (VMI), Global 
Abstract

40 Tidal measurements are of great significance since they may provide us with essential 41 data to apply towards protection of coastal communities and sea traffic. Currently, the 42 tide gauge stations, satellite-based, pressure-based and ultrasonic-based techniques are 43 commonly used. However, with these techniques, sensors have to be either floated on 44 the sea surface or sunk onto the seafloor. The former option makes it difficult to conduct the tide measurements in high traffic maritime sea channels, and the latter option requires the construction of undersea electric and telecommunication infrastructures to support real time monitoring. On the other hand, with muography, sensors can be located underneath the seafloor inside, for example, an undersea tunnel where the electric and telecommunication infrastructures are more readily available. In this work, the world's first under-seafloor particle detector array called the Tokyo-bay Seafloor Hyper-Kilometric Submarine Deep Detector (TS-HKMSDD) was deployed underneath the Tokyo-Bay seafloor for conducting submarine muography.

53 Time-sequential muographic data were converted to the tidal levels above the detector 54 and compared with the data acquired from the nearby tide gauge station. The results were consistent, indicating that submarine muography could be an alternative tool for tide measurements. We anticipate that if the length of the TS-HKMSDD is extended from $100 \mathrm{~m}$ to a full-scale as large as $9.6 \mathrm{~km}$ to provide continuous tidal information along the tunnel, muography will become an established standard, demonstrating its effectiveness as practical tide monitor for this heavy traffic waterway in Tokyo and in other important sea traffic areas worldwide.

\section{Introduction}

66 Sea levels have been continuously measured and modeled extensively in the last 
67 decades in order to evaluate the global and local climate change and ocean variability.

68 In particular, for coastal communities, reliable sea-level information is essential since

69 coastal flooding is increasingly occurring in many areas ${ }^{1,2}$. The heights of coastal

70 barriers or breakwaters are typically designed by considering the superimposed effects

71 of tides, surges, waves, and relative sea-level rise ${ }^{3}$. However, the distribution of tide

72 gauge stations (TGSs) is generally dispersed sparsely, and it usually depends on local

73 topography and the distribution of people, infrastructure and economic activity along

74 the coast. However, even within the Tokyo metropolitan bay area, one of the most

75 populated areas in the world, TGSs are still sparsely distributed; along the $770 \mathrm{~km}$ of

76 coast making up the Tokyo bay of Japan, there are only four TGSs with long-term data

77 taking capabilities. For the safety of coastal communities and maritime navigation,

78 understanding how coastal high waves happen, or identifying which meteorological and

79 tide conditions produce high waves are important, and for this, more detailed sea level

80 monitoring will be required because the local tides are highly variable, depending on

81 local topography and bathymetry ${ }^{4}$.

83 Remote sensing techniques provide a more flexible solution for analyzing sea level 84 changes in comparison to TGSs. The two main remote sensing techniques used are global-navigation-satellite-system (GNSS) buoys and interferometric synthetic aperture radar (InSAR). GNSS buoys are a new type of a tide gauge that has been developed with GNSS satellite positioning technology, allowing us to distribute the tide gauges in the offshore region, and it can measure tidal level with high precision and relatively fast time resolutions (30 s -1 day $)^{5}$. However, installing a large array of GNSS buoys in the

90 high traffic coastal areas is not practical due to the obstruction it would create to sea 91 traffic and the high cost of deployment. InSAR enables spatially continuous 92 measurements. InSAR has been applied to detecting water level change with $3-5 \mathrm{~cm}$ 93 accuracy over wide wetland areas $^{6-9}$ and tidal inundation, propagation and mapping the 94 tidal zone of the wetland ${ }^{10}$. However, InSAR is only applicable to detecting tidal 95 changes that occur within longer spans of time, ranging from a few days to a few 96 weeks $^{9,11}$. For example, the revisit interval of current in-orbit InSAR satellites, such as 97 TerraSAR-X and COSMO-SkyMed, is $\sim 15$ days $^{5}$, which is too long to image rapid sea 98 level variations. In order to acquire data with faster time resolution, it would be 99 necessary to launch additional, shorter revisit cycle InSAR satellites. Moreover, with 
100 the current technique, horizontal and vertical motion cannot be distinguished, and only

101 the unsteady tidal contribution can be extracted by differencing two separate InSAR

102 pairs that originate from a combination of several SAR images ${ }^{12}$.

103

104 Ocean bottom pressure gauging and ultrasonic gauges are also alternative methods that

105 have been developed for detecting the sea level changes from the seafloor ${ }^{13}$. However,

106 the pressure gauging technique has an intrinsic drift error, and moreover, the sensors

107 have to be directly located on the seafloor, and thus it is challenging to prepare the

108 electric and telecommunication network that are required for real-time monitoring. Like

109 pressure gauges, ultrasonic gauges do not have to float on the sea surface, and there are

110 no intrinsic drift errors either. This technique measures the propagation time of the

111 ultrasonic signals between the sea surface and the sensor located at the seafloor.

112 However, in particular, at shallow depths of seawater near coastal areas, sound

113 propagation is strongly affected by solar radiation, seasonal cycles, mixing of the water

114 due to sea currents, and the presence of rivers or waste waters ${ }^{14}$. On the contrary, the

115 muon propagation properties are much less sensitive to the oceanic environment, e.g.,

116 variations in salinity, temperature, internal density waves in the upper-ocean, or motor

117 sound in comparison to techniques that measure acoustic signals ${ }^{15}$. More importantly,

118 since muons propagate through solid and liquid materials in a similar manner, the

119 sensors can be located underneath the seafloor; for example, muon detectors can be

120 placed inside an undersea tunnel where the electric and telecommunication

121 infrastructures are not only convenient and well-arranged but often readily available and

122 an important part of the original tunnel design.

123

124 Cosmic-ray muons are relativistic particles with a rest mass of $105 \mathrm{MeV}$. They travel

125 almost at the speed of light through any kind of material and their speed is not affected

126 by the media condition they travel as long as their energies are within the relativistic

127 region. They are produced in the Earth's atmosphere via the collision between primary

128 cosmic rays, which are mainly galactic cosmic rays (GCRs), and atmospheric nuclei,

129 such as nitrogen and oxygen. These particles are ubiquitous and thus, available

130 everywhere on the Earth. GCRs arrive at the Earth isotropically, because before arriving

131 at the Earth, GCRs are deflected multiple times during their propagation in the galaxy,

132 and lose their initial directional information. However, due to different atmospheric 
133 thicknesses and density gradients for different GCR's arrival angles, the muon energy

134 spectrum varies for different zenith angles. As a consequence, the vertical muon flux is

135 higher than the horizontal flux, but the average energy of vertical muons is lower than

136 the horizontal ones. The vertical muon flux is $\sim 10^{2} \mathrm{~m}^{-2} \mathrm{~s}^{-1} \mathrm{sr}^{-1}$, but this flux is

137 respectively reduced to $\sim 10$ and a few muons $\mathrm{m}^{-2} \mathrm{~s}^{-1} \mathrm{sr}^{-1}$ at the depths of $10 \mathrm{~m}$ and 100

$138 \mathrm{~m}$ in water $^{16}$. Muons are called heavy electrons. Due to the mass of a muon, they

139 experience much less radiative energy loss processes (bremsstrahlung, direct pair

140 production, and photonuclear interaction) than electrons, and consequently are much

141 more penetrative than electrons. In conjunction with this penetrative nature and this

142 universality, muography has been widely applied to visualizing the internal structure of

143 gigantic objects such as volcanoes, highway \& railway tunnels, natural caves, and

144 cultural heritage in Africa ${ }^{17,18}$, the Americas ${ }^{19,20,21}$, Asia ${ }^{22,23,24,25,26,27,28,29,30}$, and

145 Europe $^{31,32,33,34,35,36,37 .}$

146

147 Undersea particle detectors have been deployed on the seafloor at large depths: in the

148 past DUMAND ${ }^{38}$ and presently ANTARES $^{39}$ and the under construction detector

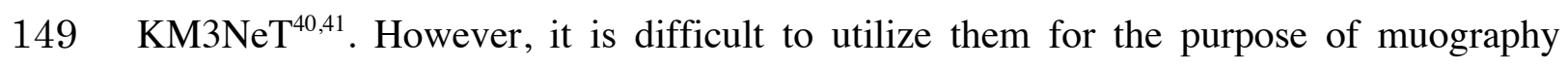

150 because they are originally designed for the detection of neutrino (another elementary

151 particle which is very light and extremely difficult to detect). Recently KM3NeT has

152 measured $^{42}$ the muon flux as a function of the depth reporting an uncertainty on the

153 measured absolute value of about $15 \%$. For the purpose of muography, being only the

154 variation on the muon flux important, the relative values are important. This will reduce

155 the total uncertainties to about $9 \%$. The main systematic uncertainties are due to the

156 reduced efficiency of the photomultiplier tubes (PMT), due to the combined effect of

157 sedimentation and biofouling effect ${ }^{40}$, and to the variation of the sensitivity to

158 Cherenkov radiation due to change in turbidity (absorption length) within sea water. In

159 addition to these in these submarine detectors, the optical sensors are anchored to the

160 seafloor by weight at the bottom and equipped with a buoy at the top (subsurface

161 mooring). There are several negative issues associated with subsurface mooring when

162 applied to muography, which include the stretching of the tether string as it ages and

163 gradual sinking of the anchor by its weight on unconsolidated sediment. Summarizing

164 the total uncertainty does not allow the measurement of depth variations of the orders of 165 meters. 
167 The world's first under-seafloor detector array for conducting submarine muography 168 called the Tokyo-bay Seafloor Hyper-Kilometric Submarine Deep Detector 169 (TS-HKMSDD) was deployed underneath the Tokyo bay seafloor on March 5, 2021

170 (Figure 1). The ten installed muon sensor modules (MSMs) were anchor-bolted inside 171 the undersea tunnel called the Tokyo-bay Aqua-tunnel; this tunnel provides an ideal 172 environment for submarine/under-seafloor muography and overcomes the 173 aforementioned issues. The detector collects near vertical muons after they have passed 174 through the seawater and upper layer of the seabed of Tokyo-bay existing directly above 175 the tunnel. The time-sequential muographic data were collected and converted to the 176 tide levels above the detector. The results were compared with the data acquired from 177 the nearest neighbor tide gauge station. The potential and prospects of this first 178 combination of muography in the undersea tunnel environment is discussed in the 179 following sections.

180

181

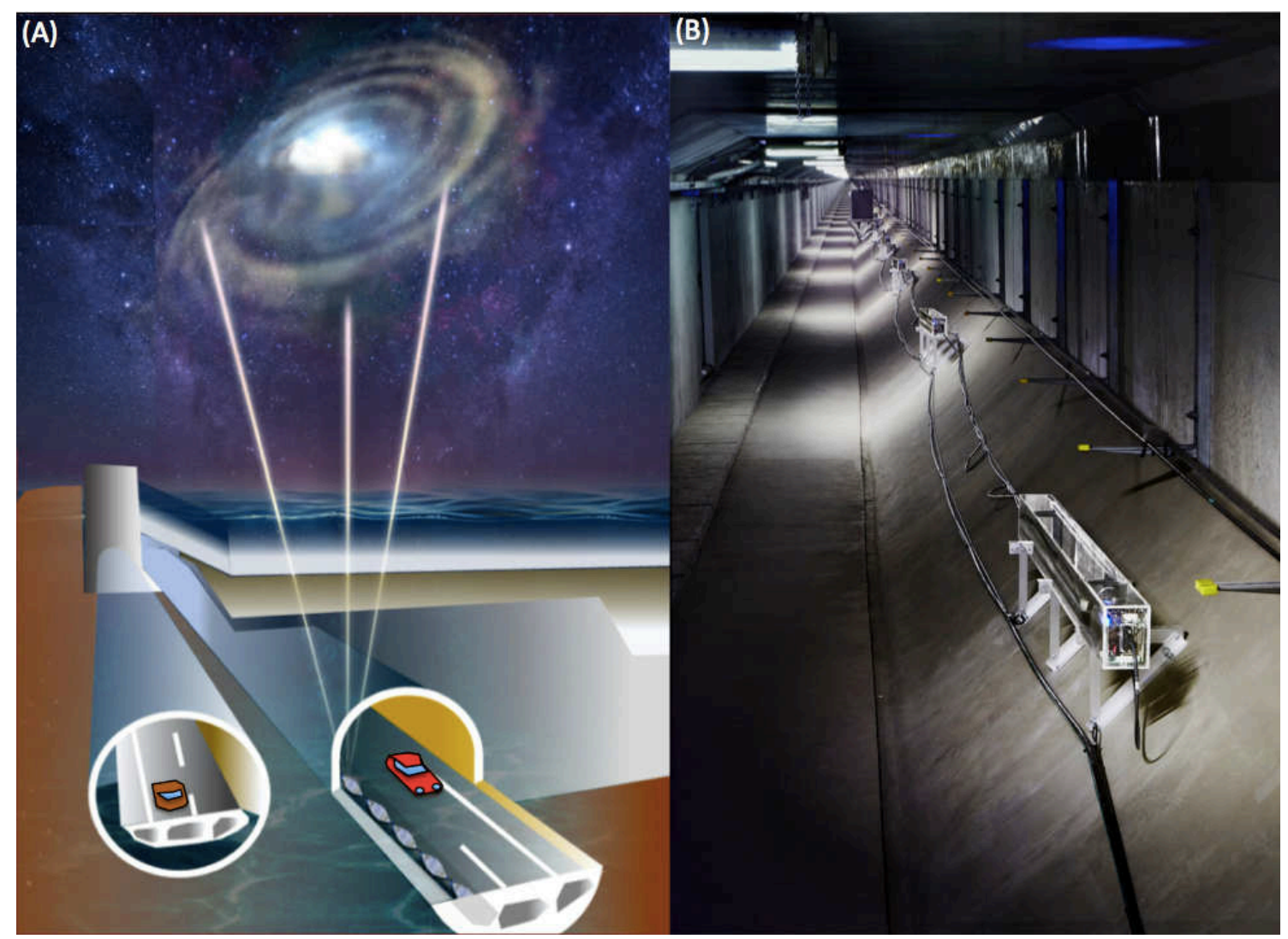

183 Figure 1. Conceptual view of the Tokyo-bay Seafloor Hyper-Kilometric Submarine 
184 Deep Detector (TS-HKMSDD) deployed underneath the Tokyo bay seafloor (A) and 185 the photograph (B). HKMT drew this image and holds the copyright. HKMT holds the 186 copyright of the photograph.

\section{Results}

190

191 The Tokyo Bay Aqua-Line (TBAL), which is also known as the Trans-Tokyo Bay 192 Expressway, is a combined bridge and tunnel structure spanning the entire width of 193 Tokyo Bay, Japan (Figure 2). Tokyo Bay has some of the highest maritime traffic sea 194 channels in the world, and 500-1000 ships travel over or under the span of TBAL every 195 day. TBAL consists of a 4.4-km long bridge (30\% of TBAL) and a 9.6-km long tunnel 196 (70\% of TBAL) underneath the bay. The tunnel section is called the Aqua-Tunnel. The 197 average sea depth is $20 \mathrm{~m}$ in most of the region where the Aqua-Tunnel was constructed, 198 and the tunnel was constructed at a depth of $20 \mathrm{~m}$ underneath the seafloor. In this work, 30 muographic sensor modules (MSMs) were deployed inside the Aqua-Tunnel to construct a linear array of MSMs called the Tokyo-bay Seafloor Hyper-Kilometric 201 Submarine Deep Detector (TS-HKMSDD). Each MSM consists of two scintillation 202 detectors, a high-voltage power supply unit (HVU) (Technoland Z-SYS 070HV), and a 203 discriminator-coincidence unit (DCU) (Technoland Z-SYS 070DC) (Figure 3). When a 204 muon passes through the detector, the scintillation light is transported to the 205 photomultiplier tube (PMTs) (HAMAMATSU R7724 ASSY) attached to these plastic 206 scintillators (10 cm wide, $150 \mathrm{~cm}$ long) (ELGEN EJ-200) via acryl light guides (Figure 207 3A). The signal outputs from these PMTs are transferred to the DCU to select only the 208 events that pass through both of these scintillators at the same time. Although we did 209 not expect secondary cosmic charged particles at a depth of more than $40 \mathrm{~m}$ water equivalent (m.w.e.), a 2-cm thick lead block was inserted between these plastic

212 the tunnel (see the Method section for a more detailed description about the MSM 213 design). Tokyo Bay was chosen for conducting submarine muography because various 214 maritime data sets including seawater and atmospheric temperature data, barometric 215 data, salinity data, wind speed and direction data, precipitation data, humidity data, etc. 216 are available, enabling more comprehensive comparison and evaluation of our 
217 muographic results.

218

(A)
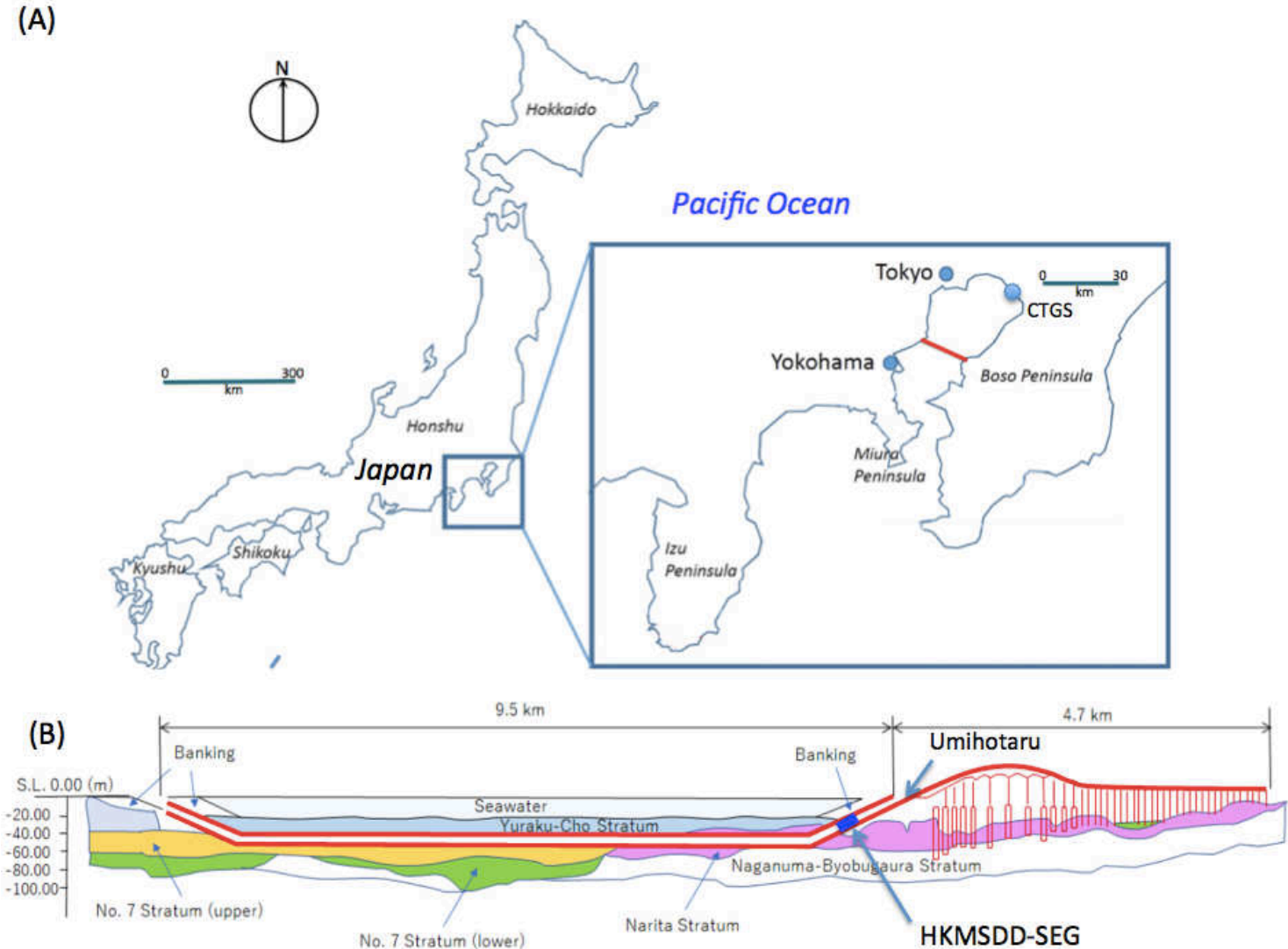

No. 7 Stratum (lower)

HKMSDD-SEG

220 Figure 2. Location of the Tokyo Bay Aqua-Line (TBAL) in Japan (red lines) (A) and

221 the cross-sectional view of the tunnel section (Aqua-tunnel) of TBAL (B). The symbols

222 CTGS and HKMSDD-SEG respectively indicate the locations of the Chiba tide gauge 223 station and the HKMSDD segment. The name Umihotaru indicates the service area that 224 marks the transition between the bridge and tunnel part. HKMT drew the map and the 225 image with the Microsoft PowerPoint software and holds the copyright. 


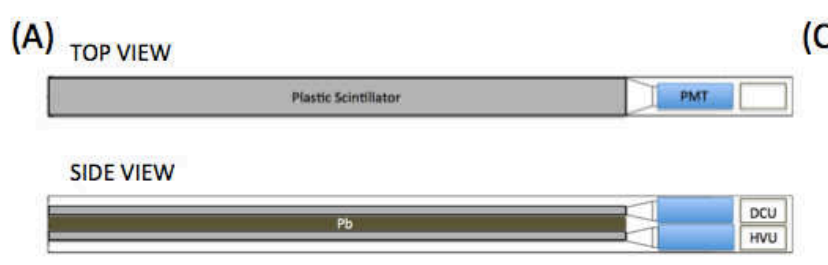

(B)

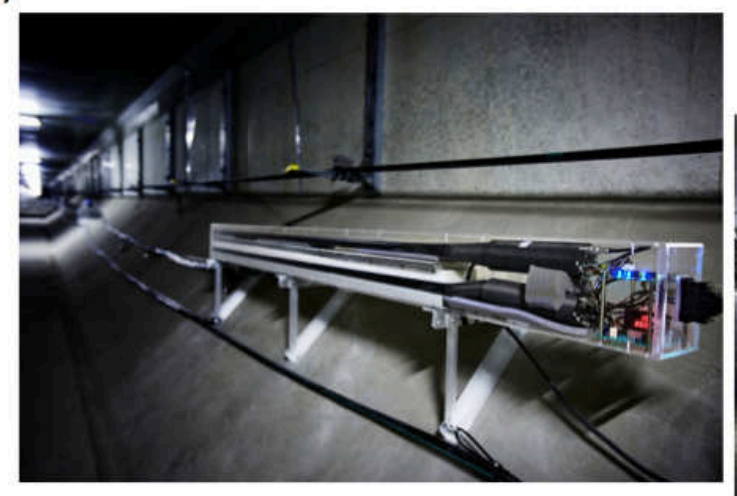

(E)

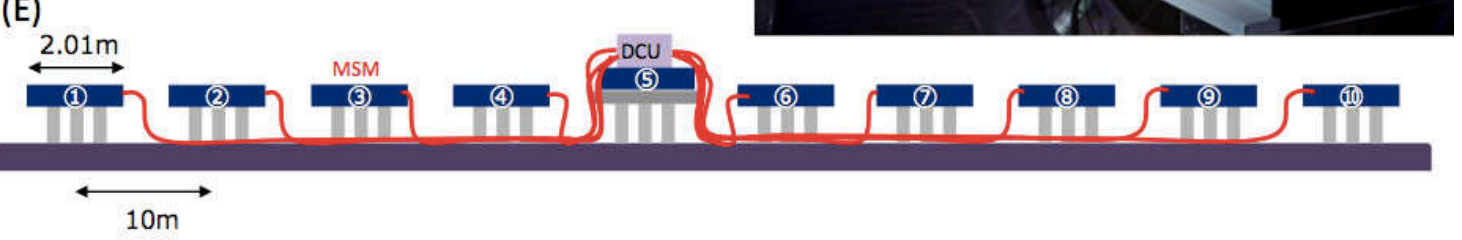

(C)

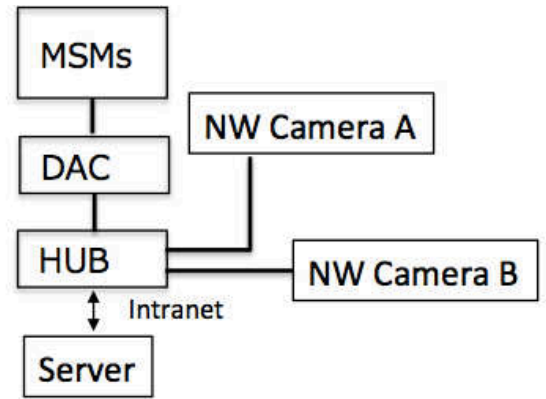

(D)

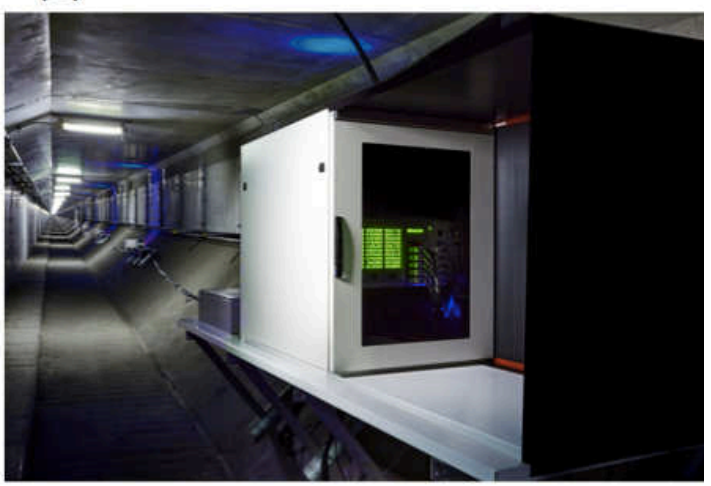

Figure 3. Configuration of the HKMSDD segment. The schematic of the muographic sensor module (MSM) (A) is shown along with a photograph of the MSM (B). The abbreviations DCU and HVU respectively indicate the discriminator-coincidence unit and the high-voltage power supply unit. The block diagram of the data collection scheme (C) is shown along with a photograph of the Data Acquisition Center (DAC) (D). The network cameras (NW Cameras) are respectively used for monitoring the MSM LEDs and the DAC 7-segment LEDs. The HKMSDD server hosts a closed network. The schematic view of the HKMSDD segment is also shown (E). HKMT holds the copyright of the photographs.

An HKMSDD segment consists of ten MSMs, each spaced evenly at an interval of $10 \mathrm{~m}$ and the data acquisition center (DAC) located at the center of the segment (Figure 3E). Since the size of the scintillator of each MSM is $1500 \mathrm{~cm}^{2}$, each HKMSDD segment has an active area of $1.5 \mathrm{~m}^{2}$. Each segment measures $100 \mathrm{~m}$ in length (See Method section for more detailed description about the HKMSDD segment). In this work, one HKMSDD segment (SEG) was installed in the Aqua-Tunnel. The SEG was placed 
245 within the region 500-600 $\mathrm{m}$ from the station called Umihotaru (the Japanese word for

246 Vargula hilgendorfii, a local bioluminescent, ostracod crustation) that marks the

247 transition between the bridge and tunnel part. Umihotaru is located in the middle of

248 Tokyo Bay, and is located at almost the same distance from three major coastal cities

249 (30 km from Tokyo city, $27 \mathrm{~km}$ from Chiba city and $22 \mathrm{~km}$ from Yokohama city)

250 (Figure 2A). Directly above the tunnel in which the SEG is installed is a $10 \mathrm{~m}$ thick

251 rock overburden (the seabed) and approximately $20 \mathrm{~m}$ thick column of water. (Figure

252 2B). The operation of the SEG started on March 5, 2021. The muon signals detected by

253 MSMs are transferred to DAC, counted, and transferred in real time to the external

254 server located in Kyoto, Japan. These numbers of counts are also locally displayed on

255 the LED panel attached to DAC. Each DCU has an LED light that flashes when the

256 detector is triggered, and both local LED panels and LED lights are monitored with the

257 surveillance camera for remote monitoring.

259 Figure 4 shows the time-sequential plot of the lunar-daily (24 hours and 50 minutes)

260 muon counts. The data were taken in the period between March 5 and May 10, 2021.

261 Here, the lunar day refers to the period between moonrises. Therefore, by taking the

262 lunar-daily average, instead of a standard day of 24 hours, variations in the astronomical

263 tide levels are canceled. The muon rate is almost constant and the average muon counts

264 per lunar day and standard deviation (S.D.) were respectively 1,145,080 and 2,780 ( 2.5

265 per mille). As is described later, this fluctuation corresponds to the systematic error in 266 determination of sea level of $5 \mathrm{~cm} \mathrm{S.D.} \mathrm{(see} \mathrm{Figure} \mathrm{6).}$

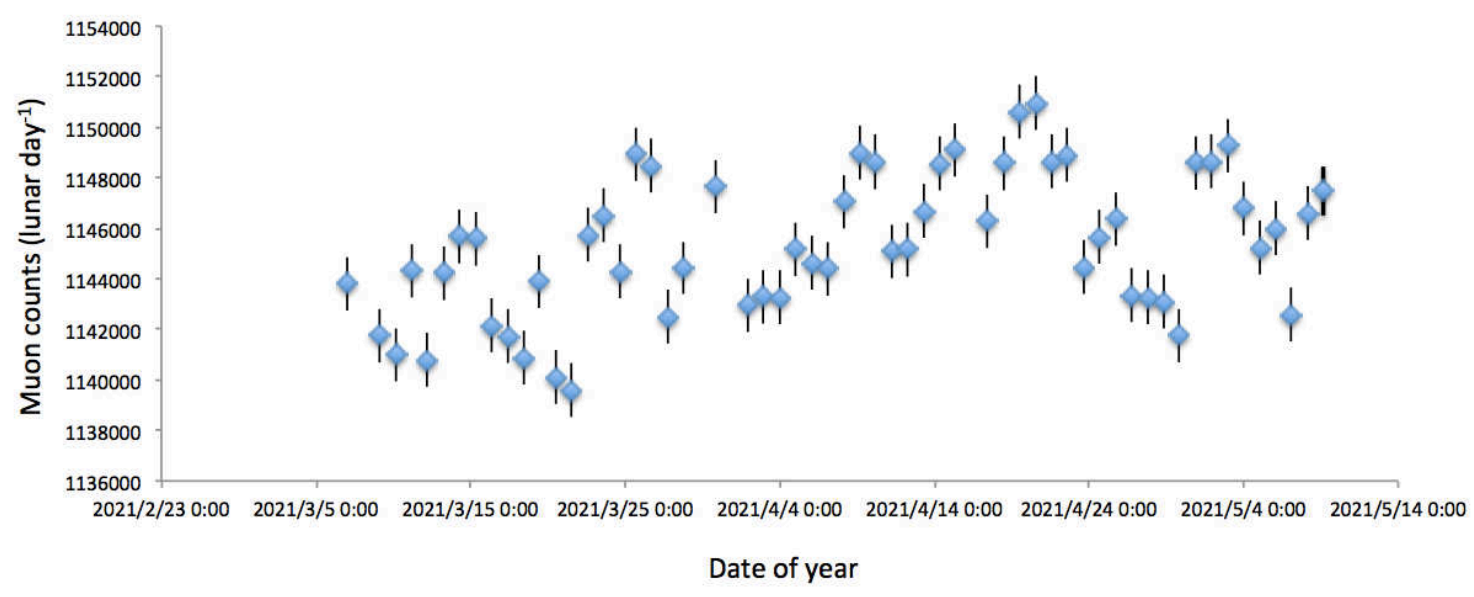

269 Figure 4. Time-sequential plot of the lunar-daily muon counts. 
272 Variations in the atmospheric pressure are compensated with the column density of 273 seawater and thus, it was expected that the muon counts are insensitive to the 274 atmospheric pressure variations. Muon counts are also insensitive to the sea level 275 variations due to the thermal expansion of the sea because this kind of variation does 276 not change the column density above the detector. The seawater density is also a 277 function of salinity, but again the density variations of seawater will be compensated 278 with the atmospheric pressure.

280 Figure 5A shows the time-sequential plot of the number of muon counts collected every 2815 minutes. The data points were smoothed by taking a moving average with a time 282 window of 2 hours. The daily tide variations along with a longer cycle of spring and 283 neap tides are clearly seen as an anti-correlation with the results from the Chiba tide 284 gauging station (CTGS) (Figure 5B). When the tide level rises, the muon counts 285 decrease and vice versa. The height difference between high and low tides during the 286 neap tide period was $20-30 \mathrm{~cm}$, and this level of tide variations can be clearly 287 distinguished with the current HKMSDD segment, justifying the tide gauging accuracy 288 we derived in the previous paragraph. 

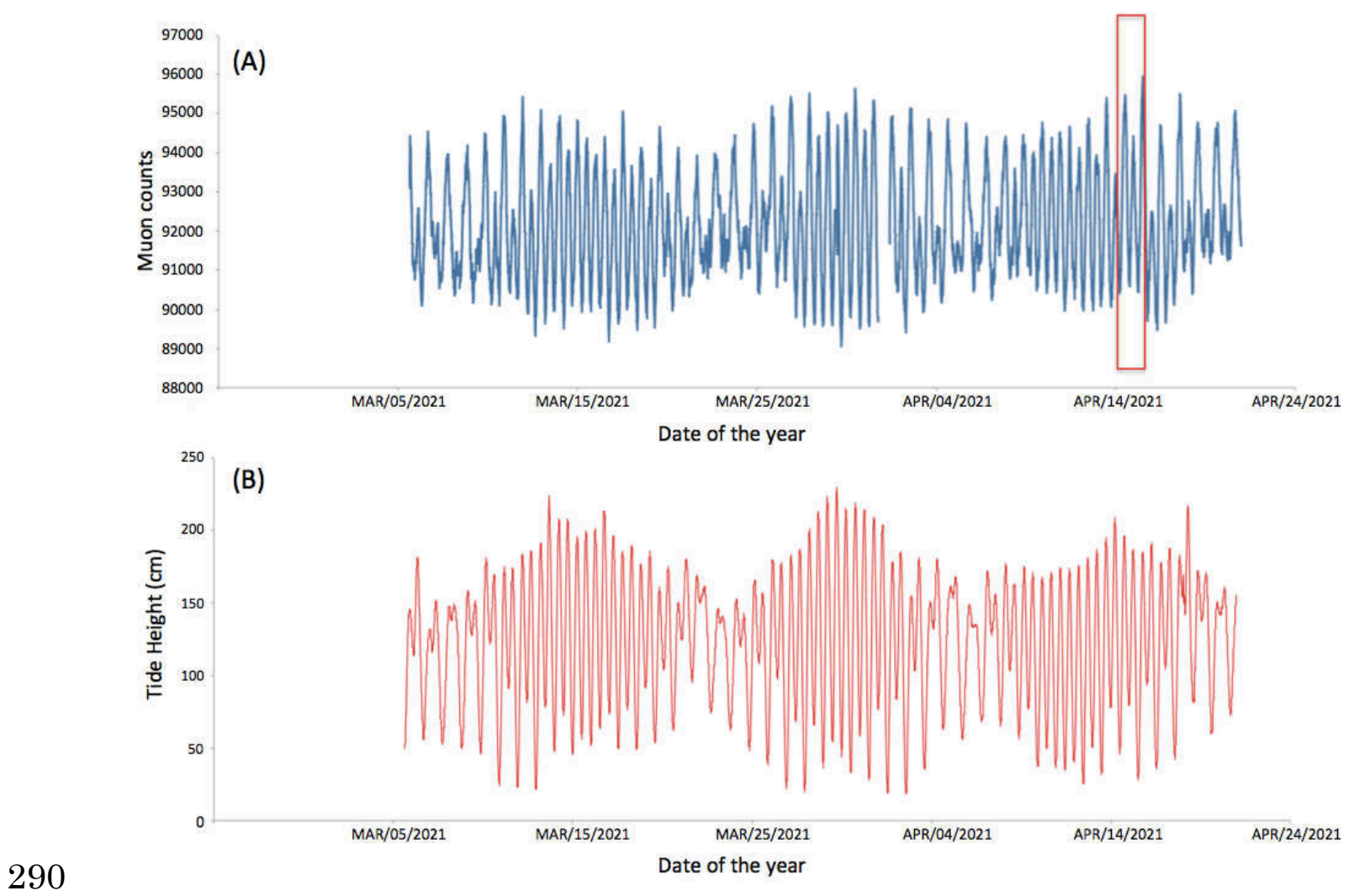

Figure 5. Time-sequential plot of the number of muon counts collected every 5 minutes

292 (A) and the tide gauging results measured at the Chiba Tide Gauging Station (B) ${ }^{43}$. The 293 red box indicates the period we used for the detailed analysis in Figures 6 and 8.

296 The nearest neighbor tide station was located at the Chiba port $(25 \mathrm{~km} \mathrm{NE}$ of 297 Umihotaru). Since the distance between the Chiba tide gauge station and Umihotaru is 298 close enough, the astronomical tide variations could be directly compared between the 299 muographic data and the CTGS data within the time scale of 5 minutes. Figure 6 300 compares the tide levels converted from the muon counts with the tide gauging results 301 measured at CTGS. In this plot, the dates when the observed tide levels were close to 302 the astronomical tide estimation were chosen. As is described later, generally, tidal 303 levels cannot be directly compared with the muographic data due to the inverse 304 barometer effect (IBE), and thus in Figure 6, the dates when the minimum barometric 305 effect was observed have been chosen. 


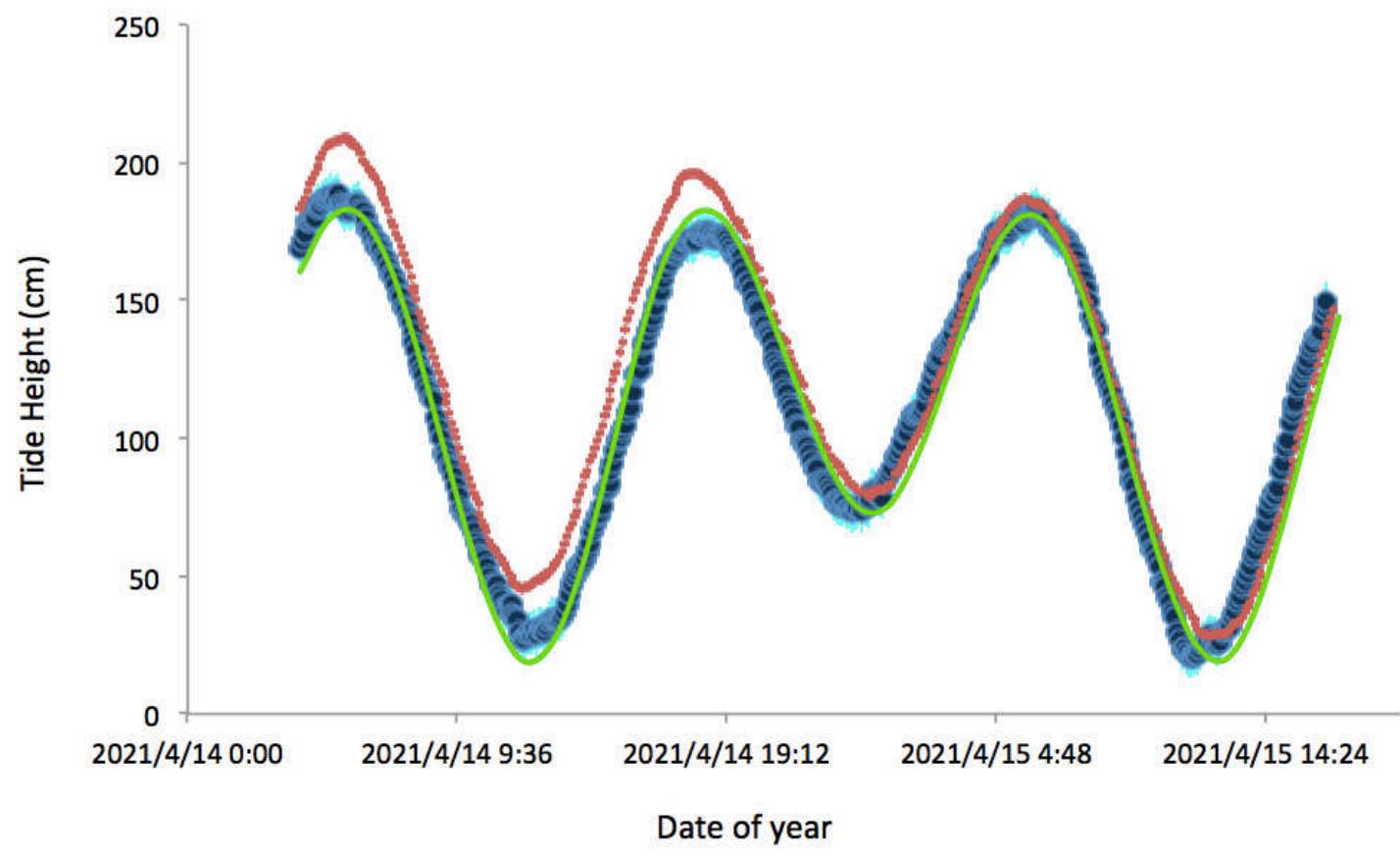

Figure 6. Tide levels converted from the muon counts. The data points (dark blue 309 filled circles) are shown along with the statistic error bars (1 standard deviation) (sky 310 blue lines). The tide gauging results measured at CTGS (red filled circles) and the 311 theoretical calculation results of the astronomical tide levels (green line) are also shown (43).

315 Since muography measures the integrated density along the muon paths, the local 316 seafloor topography and the average density of the seabed above the tunnel affects the 317 absolute sea level gauging. For example, uncertainty of $5 \mathrm{~cm}$ for the topography or that 318 of 1 per mille in seawater density will respectively correspond to an uncertainty of 7.5 $319 \mathrm{~cm}$ and $2 \mathrm{~cm}$ in sea level when considering the sea depth of $20 \mathrm{~m}$ and assuming the 320 seabed density of $2.5 \mathrm{~g} / \mathrm{cm}^{3}$. For this reason, the technique to measure the relative tide 321 variations without the necessity of the knowledge of these external factors was 322 developed by using a simple relationship between muon flux and matter thickness they 323 travers (see Figure 7).

325 In muography, the muon range as a function of the incident muon energy is 326 incorporated in the open-sky muon spectrum as a function of the zenith angle $(\theta)$. Once 327 both the muon path length and the average density along the path are known, the 
thickness $(X)$ can be calculated by multiplying them, and thus the minimum energy $\left(E_{\mathrm{c}}\right)$

329 of muons that can penetrate through a material. By integrating the open-sky spectrum $I$

$330(E, \theta)$ from $E_{\mathrm{c}}$ to infinity, we obtain the integrated muon intensity $N\left(E_{\mathrm{c}}\right.$,), which

331 represents the number of muons that have enough energy to escape from the target of 332 interest:

$$
N\left(E_{c}, \theta\right)=\int_{E c}^{\infty} I(E, \theta) d E
$$

where $I(E, \theta)$ is the zenith-angle-dependent open-sky muon energy spectrum, and $E_{\mathrm{c}}$ is the cutoff energy as a function of thickness, $X$. Due to the geometric acceptance of the detector, and the slant depth of both seawater and seabed, most muons arrive from the near vertical direction $(50 \%, 70 \%$, and $90 \%$ of the total muons respectively arrive within the angle region $0^{\circ}-20^{\circ}, 0^{\circ}-33^{\circ}, 0^{\circ}-50^{\circ}$ from zenith). The integrated muon flux calculated with Eq. (1) is shown in Figure 7 for small variations in the matter thickness muons traverse. In this plot, only the range between $4,000 \mathrm{hg} \mathrm{cm}^{-2}$ to $4,100 \mathrm{hg} \mathrm{cm}^{-2}$ is shown. As shown in this figure, if the deviation $(\Delta X)$ in $X$ in Eq. (1) is significantly smaller than $X$, the relative penetrating muon flux $(\Delta N)$ is a linear function of $\Delta X$. By utilizing this flux-thickness relationship, the muon counts were calibrated with the astronomical tide height variations measured at the Chiba tide gauge station as reference data and only the relative difference $(\Delta X)$ was considered for conversion from the muon counts to the tide height. This method has an advantage for cases when we do not have accurate information about the factors that increase the uncertainty in the total rock-water thickness $X$. As shown in Figure 6, once the relative muon counts $(\Delta N)$ calculated by subtracting the local maximum from the local minimum respectively were observed at 0:00 and 6:00 April 15, these data were calibrated with the low and high tides respectively observed at 0:10 and 6:00 April 15, the next low tide height at 12:25 on the same day was reproduced accurately with this technique. In the period between 21:00 April 14 and 17:00 April 15, muographic results, astronomical tide, and the actual tide observed at the Chiba tide gauge station were almost the same. However, before this period, muographic results were significantly deviated from the tide gauging results. This reason will be discussed in the next section. 


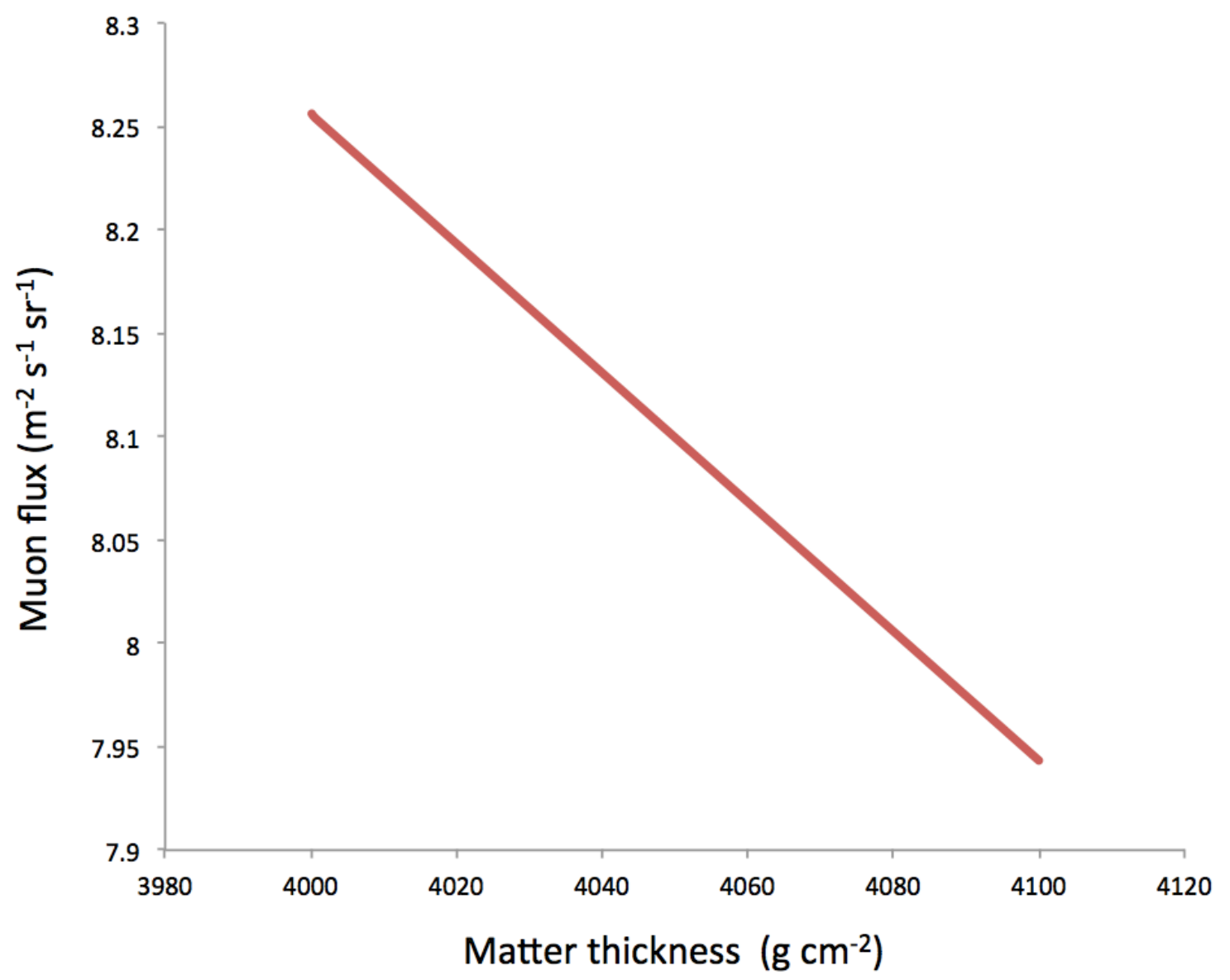

361 Figure 7. Muon flux expected at the Hyper-Kilometric Submarine Deep Detector 362 (HKMSDD) segment placed within the region 500-600 $\mathrm{m}$ from Umihotaru (SEG1) for 363 various matter thicknesses.

364

365

\section{Discussion}

368 It was shown that muography has the potential to provide an alternative and practical 369 tide measurement technique that can complement preexisting tide gauging techniques. 370 This technique enables us to measure tide levels at the locations where the conventional 371 tide measurements are difficult to conduct. However, since muography measures the 372 integrated mass above the detector, the measurements are influenced by some factors 373 that do not have to be considered with the conventional techniques.

375 In the near future, TS-HKMSDD will be extended to a full scale of $9.6 \mathrm{~km}$ throughout 376 the Aqua-tunnel. In this section, we discuss how the undersea environment can possibly 


\section{6}

affect the muographic measurements and how these errors can be corrected or suppressed. After that, we summarize our prospects based on the potential of the proposed full-scale detector array.

Atmospheric Effect. Most muons are generated at the lower part of the stratosphere and lose their energies during their propagation through the troposphere. These muon energy losses depend on the "thickness" of the troposphere. When high pressure covers the area of the observation, less muons arrive, and vice versa. These atmospheric pressure variations affect the time-dependence of the muon flux on ground ${ }^{44}$; hence muographic results are affected accordingly. However, for submarine muography, the muon flux is not affected by these atmospheric pressure variations since fluctuations in the sea level have a complementary relationship with the atmospheric pressure fluctuations above. This effect is called inverse barometer effect (IBE). If the atmospheric pressure is reduced by $1 \mathrm{hPa}$, the sea level rises by $1 \mathrm{~cm}$. On the other hand, for the purpose of the muographic tide gauging, there is a contributing factor to the actual tide height. In Tokyo, meteorological information including the atmospheric pressure is collected every 10 minutes and reported to the public ${ }^{45}$. Figure $8 \mathrm{~A}$ shows barometric variations measured in the same period of Figure 6 in Tokyo, Japan, which is located $30 \mathrm{~km}$ north from Umihotaru. Although the pressure data were collected on land, they were converted to the values at sea level. As was described in the previous section, the muographic data shown in Figure 6 (April 14-15, 2021) matched well with the astronomical tide variations but there was a significant deviation from the Chiba tide gauge station data. It was expected that this deviation came from this inverse barometric effect. In Figure 8B, the muographic results with the barometric correction are shown. There is also a stratospheric temperature effect on the muon flux ${ }^{44,46,47}$, but this effect only affects high-energy muons with energies above a few hundred $\mathrm{GeV}$, which are far beyond the energies $(\sim 10 \mathrm{GeV})$ we are discussing here, and therefore it is beyond the scope of this work. 

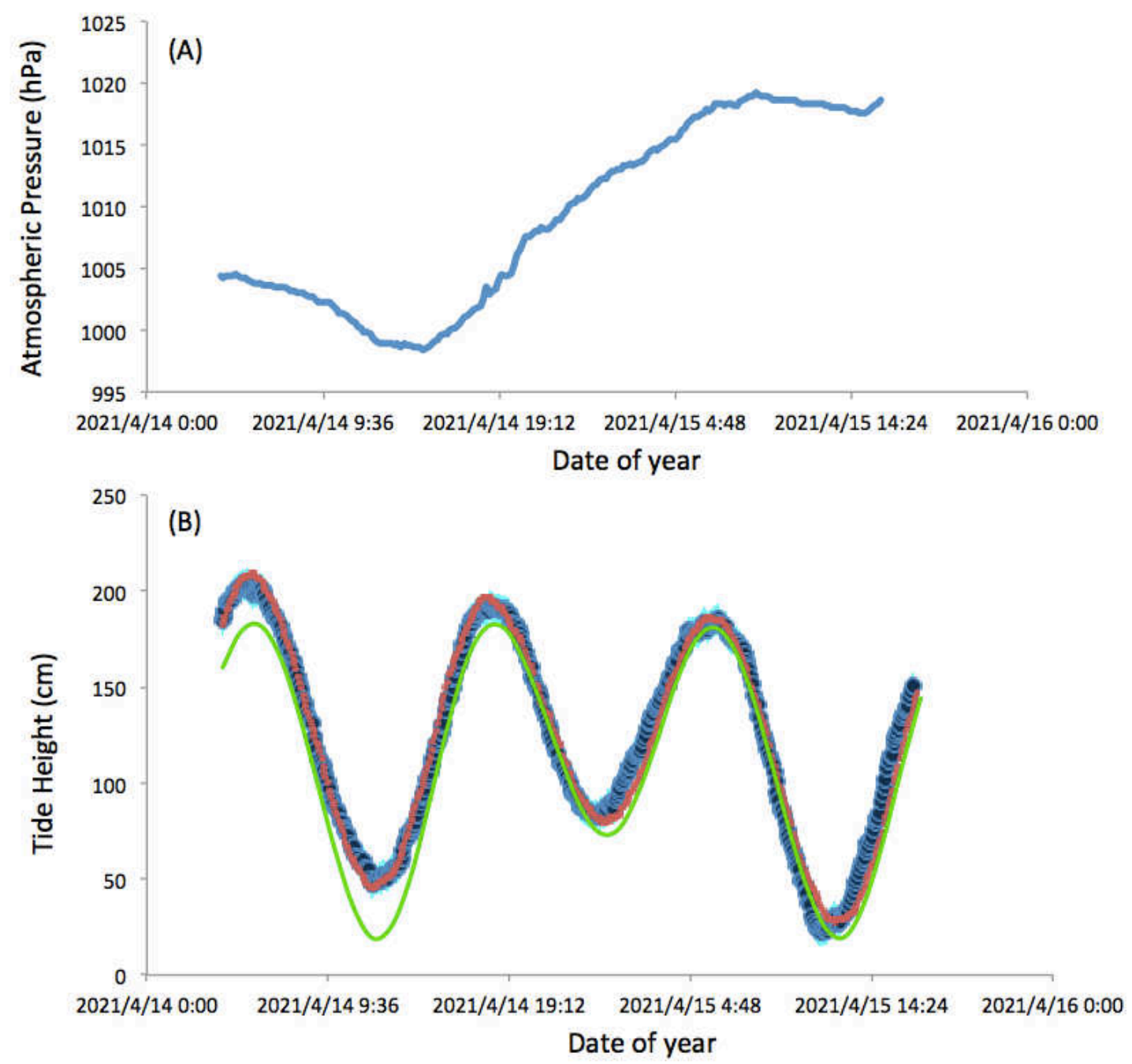

409 Figure 8. Hourly barometric variations measured in Tokyo, Japan (A). The values were 410 converted to those at sea level. Tide levels converted from the muon counts with the 411 barometric corrections. The data points (dark blue filled circles) are shown along with 412 the statistic error bars (1 standard deviation) (sky blue line). The tide gauging results 413 measured at CTGS (red filled circles) and the theoretical calculation results of the 414 astronomical tide levels (green line) are also shown ${ }^{43}$.

418 TS-HKMSDD as a tide monitor on the heavy traffic waterway. The undersea tunnels 419 are constructed to allow shipping to pass above them without traffic congestion. Bridges 420 with opening or swinging mechanisms also allow shipping to pass, but they can cause 421 traffic congestion. Moreover, longer bridges are more difficult to open or swing. 
422 Alternatively, building higher bridges will help to avoid having to add opening and

423 swinging mechanisms; however, these bridges are more costly and more fragile against

424 high winds. Inversely, the locations where the undersea tunnels were constructed are

425 prone to having both heavy automobile and maritime traffics. Therefore, it is difficult to

426 perform conventional tide measurements with buoys in the waters above these undersea

427 tunnels in spite of the advantages they provide for the safety of the navigation. As a

428 consequence, there is a clear incentive to investigate if muography can be used to fill in

429 this gap and conduct tide measurements in heavy traffic waterlines that are now 430 vulnerable.

431

432 Urbanizations have historically occurred in the bay areas because they are relatively 433 safer against storm surges in comparison to land facing the open ocean. Storms 434 occurring over the open ocean can generate large waves called swells. Large swells 435 generated by the storms propagate outward from the storm, traveling over long 436 distances across the ocean, but their energy is conserved or weakly dissipated during 437 their propagation, and they release most of their energy on the open coasts with high 438 waves (sometimes more than $10 \mathrm{~m}$ ). The negative effects of large swells are generally 439 mitigated by using some sort of blocking mechanism, like narrow entrances that 440 characterize many of the bays ${ }^{48}$. However, some of the swells can nonetheless pass 441 through bay entrances, and may consequently cause damage to the coastal infrastructure. 442 For example, the largest presence of such bay swells occurs in the region of Central Bay 443 between the Bay Bridge and the Richmond-San Rafael Bridge, San Francisco, $\mathrm{CA}^{49}$. 444 Another region that sometimes attracts extraordinarily large waves is Tokyo Bay. For 445 example, the swells generated by Typhoon-15 reached all the way to Tokyo Bay and 446 damaged the breakwater of Yokohama port in 2019. After analyzing the meteorological 447 data collected there, it was found that the ocean-driven swells had overlapped with the 448 local waves and the wave height reached $5.57 \mathrm{~m}$. By considering the astronomical tide 449 and the wave pressure applied to the breakwater, it was estimated that the maximum 450 height of the wave reached $9.18 \mathrm{~m}$ at the coast $\mathrm{t}^{50}$. As is evident in such an example, these 451 ocean-driven swells have a potential impact on coastal land. However, the swell heights 452 are difficult to predict ${ }^{51}$. Utilizing trans-bay undersea tunnels, muography offers an 453 alternative solution to measure the tidal levels on heavy traffic water lines from 454 locations underneath the seafloor. This technique is applicable to waterways throughout 
the world with undersea tunnels.

457 Understanding of the regional tide streams in the inner bay is important for the safety of 458 navigation and environmental assessments, as well as studying about the regional 459 seawater circulation types and pollution distribution. For this reason, tidal flow fields 460 have been numerically modeled in various waters ${ }^{52-56}$. In order to conduct the tidal 461 stream simulations, the boundary conditions have to be set between the region in which 462 the simulations are conducted and the coast or the region in which the simulations are 463 not conducted. In these simulations, which are designed to reproduce the tidal stream as 464 a result of tidal level variations, tidal levels are given as the boundary condition, and 465 therefore the accuracy of these values will directly influence the quality of the 466 simulations. Conventionally, the tidal data obtained from the tide gauge stations have 467 been used as the boundary condition. However, since the locations of these tide gauge 468 stations are spatially dispersed, the data have to be interpolated. As a result, the 469 interpolated data have a tendency to be more erroneous as a function of the distance 470 from the stations. In order to solve this problem, other researchers have developed 471 numerical-model-based interpolation methods ${ }^{57}$. Undersea muography will provide 472 alternative and complementary boundary conditions to apply to these tidal flow field 473 simulations. A full-scale extension of TS-HKMSDD will constrain the modeling results 474 of the tidal stream in Tokyo Bay. The final deployment of $\sim 100$ HKMSDD segments 475 across Tokyo Bay would directly provide the open boundary condition for the modeling 476 of the northern half of Tokyo Bay. The HKMSDD segments are applicable to other 477 undersea tunnels in the world. For example, the Transbay Tube in San Francisco, CA. 478 As can be seen in Figure 9A, a full-scale deployment of HKMSDD segments 479 throughout the Transbay Tube would provide the open boundary condition in the 480 similar way to model the tidal current in the southern part of San Francisco bay. 
(A)

(B)
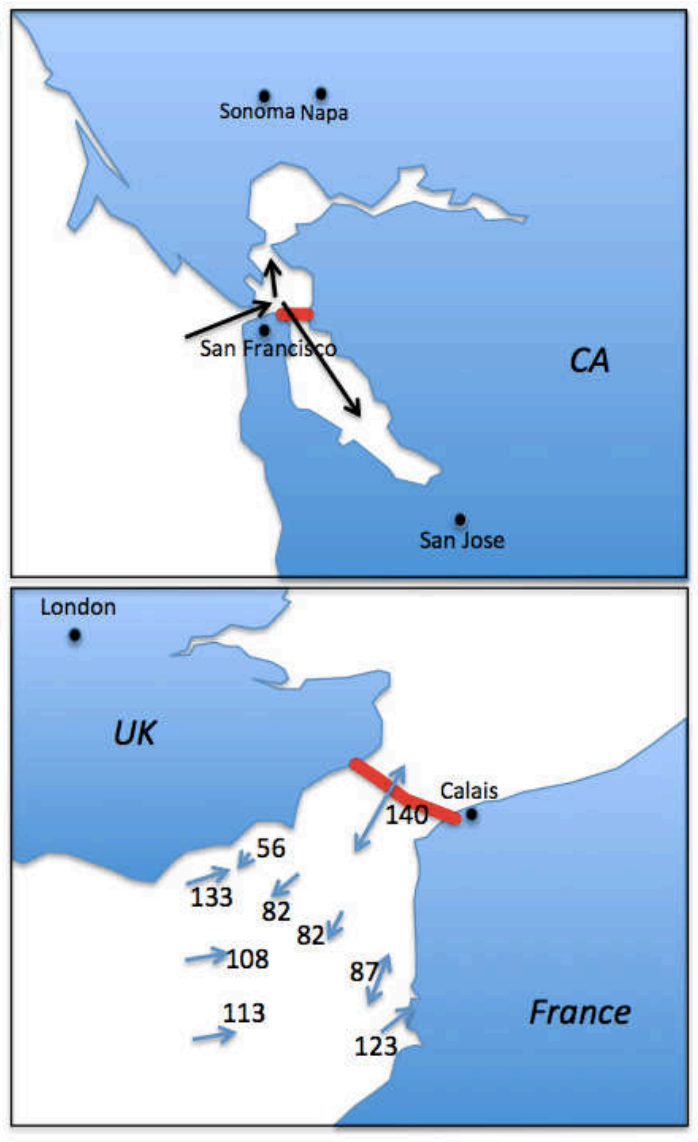

(C)

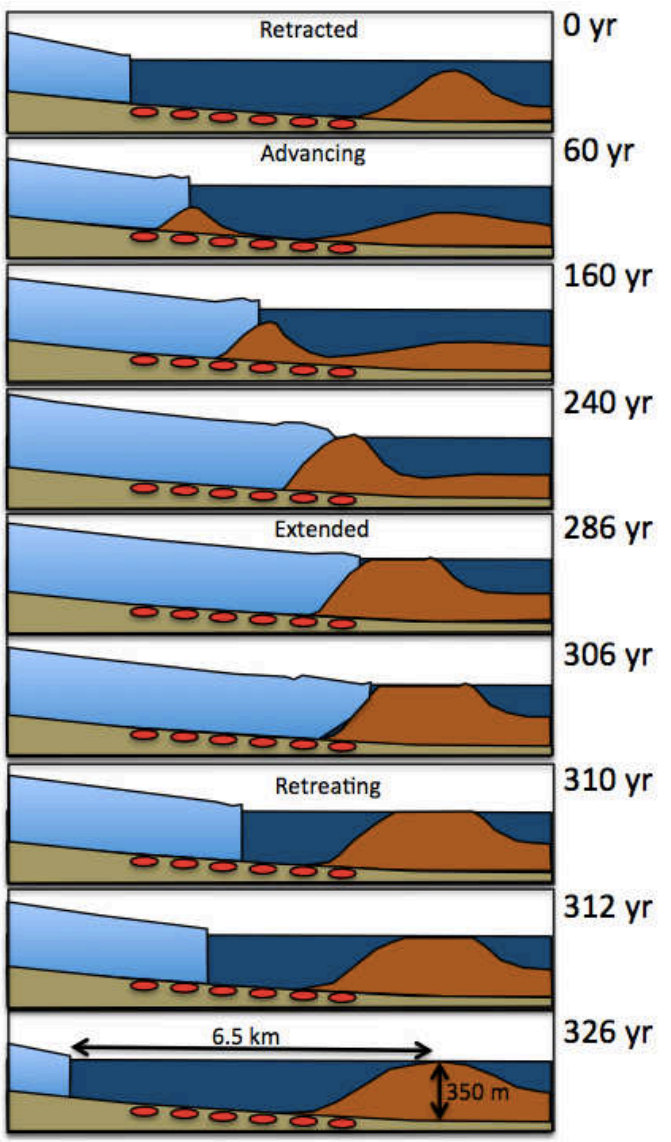

484 Figure 9. Possible future HKMSDD deployment sites: (A) Transbay Tube, San 485 Francisco, CA, (B) Channel Tunnel, UK/France, and (C) Glacier Upsala, Patagonia, 486 Chile. Red lines in (A) and (B) indicate the undersea tunnels. Black arrows in (A) 487 indicate the direction of the pacific swells ${ }^{49}$. Blue lines in (B) indicate the spring 488 maximum current vectors. The numbers indicate the speed in units of $\mathrm{cm} / \mathrm{s}^{66}$. Red oval 489 shape symbols in (C) indicate the hypothetical HKMSDD buried under the seafloor. 490 HKMT drew the maps in (A) and (B) with the Microsoft PowerPoint software and holds 491 the copyright. HKMT drew the image in (C) based on the work by Brinkerhoff et $\mathrm{al}^{69}$.

493 TS-HKMSDD as a tsunami monitor. Submarine earthquakes sometimes cause large 494 seafloor displacements, which subsequently may generate tsunami events. A minimum 495 triggering earthquake magnitude of 5.5 is suggested for a sufficiently large submarine 496 failure to generate a devastating tsunami and only if the epicenter is located within the 497 continental slope ${ }^{58}$, otherwise a larger magnitude of 7.0-7.5 is required ${ }^{59,60}$, A tsunami is 498 a large ocean wave that can be triggered by earthquakes, landslides, and mountain collapses. Tsunami waves generally have average wavelengths of $500 \mathrm{~km}$ with an initial 
500 propagation speed of more than $200 \mathrm{~m} / \mathrm{s}^{61}$, but since the speed tends to decrease as these

501 waves approach coastal zones, the successive waves overlap, causing wave height to

502 increase. Thus, the tsunami is potentially catastrophic to coastal cities. Another

503 contribution of TS-HKMSDD is to monitor tsunami propagation. Detecting the tsunami

504 and imaging of the wave height distribution prior to its arrival to the seacoast may be

505 possible. It has been predicted that a future large earthquake called the Nankai Trough

506 Earthquake with an assumed magnitude of $9.1^{62}$ may cause tsunami waves to arrive at

507 the coast of Tokyo Bay with a height of $2.48 \mathrm{~m}$ in Koto, $2.46 \mathrm{~m}$ in Chuo, $2.44 \mathrm{~m}$ in

508 Shinagawa, $2.40 \mathrm{~m}$ in Minato, $2.37 \mathrm{~m}$ in Ota, $2.07 \mathrm{~m}$ in Edogawa and $1.88 \mathrm{~m}$ in the

509 reclaimed land of Tokyo bay (such as Odaiba and Palette Town) respectively ${ }^{63}$. It may

510 be possible to detect this tsunami 30 to 40 minutes prior to arrival at the Tokyo coastal

511 area assuming that the tsunami travels at $30 \mathrm{~km} / \mathrm{h}$. The actual height distribution and

512 speed of a tsunami above the Aqua Line tunnel will provide quantitative information of

513 the impending tsunami before it reaches the inner parts of the bay area.

514

515 TS-HKMSDD as a sediment accumulation monitor. In the coastal area of Tokyo Bay, 516 many estuaries have been urbanized with heavy traffic in the waterways. There are 517 dozens of ports including three major ports in Tokyo Bay: Tokyo, Yokohama, and 518 Yokosuka ports. In these ports, the navigation channels and harbor basins are getting 519 shallower due to the deposition of discharged sediments from the rivers. These 520 sediments need to be continuously removed from these channels. As a consequence, 521 periodic dredging is required to maintain these navigation channels and harbors in a safe 522 and usable way. Dredging is the excavation of materials from a sea, river, or lakebed 523 and depositing them at a new location for the purpose of reshaping land and water 524 features to alter drainage, navigability, constructing dams, flood and storm protection, 525 and other controls for streams and shorelines ${ }^{64}$. However, dredging activities have 526 potential environmental impacts, either within the dredging area or the deposition site. 527 The dredging process causes sediment resuspension that increases the turbidity of water 528 as well as nutrients and pollutants dispersion, the latter that can cause local water 529 contamination, and possible ecosystem interference (by burying biological habitats, for 530 example). This problem is not restricted to Tokyo Bay, but it is a global issue, 531 applicable to many of the world's ports. Determining the optimized timing and the 532 amount of dredging is essential to minimize the impact on the environment. However, 
533 the sedimentation rate varies depending on many factors including rainfall, seasonality,

534 geology, topography, sea current, etc. and thus, it is difficult to numerically estimate it.

535 Currently, there is no in-situ method to monitor the rate of this deposition.

537 Sediment monitoring also provides useful insights into the functioning and health of an

538 estuary. Recent studies have shown that sediment loads delivered to estuaries have

539 rapidly increased as a response to the erosion caused by the loss of native vegetation 540 when farms ${ }^{65}$ or urban areas $^{66}$ are introduced to a landscape. Although this 541 estuary-filling rate is particularly accelerated following intense rainfall events, it has 542 been found that in some estuaries this rate has further accelerated during the last few 543 decades in comparison to earlier in the last century ${ }^{67}$. Compared to the vertical 544 accumulation rate, the sediment mass accumulation rate provides more quantitative 545 information about the contamination. There are density variations depending on the 546 depth of the estuarine sediment. These variations are reflected by compaction or 547 changes in the composition of the sediment ${ }^{68}$. Muography will offer a novel method to 548 monitor the sedimentation rate on the seafloor if the mass-driven sea level variation rate 549 (due to the influx from land) is sufficiently smaller than the sedimentation rate.

551 A fast sedimentation rate is not only occurring in regions near estuaries. A fast tide 552 current also accelerates the sedimentation. For example, in the Kanmon channel, Japan, 553 the seafloor was dredged twice in a last couple of decades (1.5 $\mathrm{m}$ in 2001 and $2.0 \mathrm{~m}$ in $5542006)^{69}$. The Kanmon channel is used for short-cutting the commercial waterlines 555 between Japan and the Eurasian continent. Consequently, the extensive traffic control is 556 necessary to process boats that pass through this channel every minute. In 1958, a 557 tunnel was constructed under this channel (Kanmon tunnel) to mitigate the land traffic 558 between Honshu Island and Kyushu Island, Japan. In the near future, Kanmon Tunnel 559 HKMSDD will be installed to monitor the sedimentation on the seafloor.

561 It is also known that fast tidal current of more than $200 \mathrm{~cm} \mathrm{~s}^{-1}$ has been observed in the 562 English Channel. As a result, giant tidal dunes are generated and transported on the 563 seafloor. Most of these sand bodies have been studied with side-scan imagery, 564 high-resolution seismic surveys, and bathymetry ${ }^{70,71}$. All these studies demonstrate the 565 high mobility of these sand bodies. For example, in the western channel, $8 \mathrm{~m}$ high 
566 asymmetric dunes have been monitored for four years and showed an average migration 567 of $20 \mathrm{~m} \mathrm{yr}^{-1}$ in the direction of the dominant tidal current to the north. As can be seen in 568 Figure 9B, one of the fastest spring current speed was observed above the Channel 569 Tunnel. HKMSDD installed to the Channel Tunnel can be used for monitoring such a

570 large-scale migration of sand bodies in real time to understand present-day seafloor 571 dynamics.

573 Imaging tidewater glaciers (TWG) with muography would contribute to our 574 understanding of glaciers cycles in general and their effect on recent climatic global 575 issues. It has been documented that most glaciers are melting and shrinking ${ }^{72}$, although 576 some tidewater glaciers (TWG) have actually been expanding in size recently ${ }^{73}$. In order 577 to understand this trend, it is important to know the processes and time scales of 578 sediment production, transport, and accumulation near the ablation fronts of retreating 579 tidewater glaciers. In particular, sedimentation transported to the sea via tides affects the 580 tidal water glacier periodicity. For example, Taku glacier, Alaska, has advanced by 5 $581 \mathrm{~km}$ since $1933^{74}$ while Glacier Upsala, Patagonia, is experiencing rapid calving retreat ${ }^{75}$. 582 Brinkerhoff et al. ${ }^{74}$ modeled the periodic cycles of TWG glaciers in the following way. 583 Sediment carried to the terminus is transported to the sea and deposited with a rate of $\sim 1$ $584 \mathrm{~m} \mathrm{yr}^{-1}$, forming a shoal. The shoal acts as a plug that prompts thickening and promotes 585 the growth of the glacier onto the shoal, but eventually a void at the upstream end of the 586 shoal opens due to its basal motion, and the ice and bed decouple, driving glacier retreat 587 that continues over decades until it is ready to begin the cycle anew. This process 588 repeats every $\sim 300$ years. Although it is unlikely that there are tunnels already 589 constructed underneath the seafloor near the downstream end of a glacier, if we position 590 HKMSDD there with optical submarine cable at the downstream end of the retreating 591 glacier (Figure 9C), e.g., Glacier Upsala, real-time monitoring of the aforementioned 592 process will be possible.

594 Monitoring seawater mass variations. Glacier melting from the Greenland and 595 Antarctic ice sheets could alter regional hydrology ${ }^{76}$, raise global sea level ${ }^{77}$ and 596 increase natural hazards ${ }^{78}$. The global ocean freshening due to large influx of water from 597 land changes the long-term salinity and global and local water cycles. This phenomenon 598 has been investigated at the surface of the oceans at global and local scales ${ }^{79,80,81,82}$. 
599 Recent developments in satellite technology enable tracking glacier flow in real time ${ }^{83,84}$. 600 However, due to limited mass loss observations, glacier melting is not fully understood.

601 Sea level gauging also provides indirect information about glacier melting ${ }^{85}$ since the

602 rise of sea level is a combination of glacier melting and ocean thermal expansion. Thus, 603 measurements of the global ocean freshening offers an alternative method for inferring 604 the net ocean mass changes ${ }^{86,87,88}$. Undersea muography may offer yet another 605 alternative to differentiate local temperature and salinity changes from the sea level rise 606 to derive long-term water influx from land by choosing the location where the 607 sedimentation rate is low. For example, a sedimentation rate of up to 5-10 $\mathrm{cm} \mathrm{kyr}^{-1}$ (2-5 $608 \mathrm{~cm}$ water equivalent materials are added to the seafloor every 1,000 years) was 609 measured in Sado ridge and Yamato basin at a water depth of 1,000 m, the Akita coast, 610 Japan, which is significantly smaller than the estimated value for global sea level rise 611 that ranges from 1.1 to $3.3 \mathrm{~mm} \mathrm{yr}^{-1}$, depending on the measurement method (tide gauge 612 or satellite) ${ }^{89,90,91,92}$. The result of the stable operation of the KHMSDD system, as 613 shown in Figure 4, indicates that the relative sea level changes can be observed at an 614 accuracy of $\sim 1 \mathrm{~cm}$. HKMSDD does not have intrinsic drift effect and thus can measure 615 the muon rate for many decades without maintenance.

616

617 In conclusion, we successfully obtained and reported the first result of undersea 618 muography with TS-HKMSDD. The detector has been operating stably since March 5, 619 2021, and the lunar-daily-averaged muon rate showed small fluctuations with 2.5 per 620 mille s.d. that corresponded to the error in determination of the relative water level of 5 $621 \mathrm{~cm}$ s.d. at the location of the current HKMSDD segment. The 5-minute muon rate 622 showed clear anti-correlation with the tidal levels observed at the nearby tide gauge 623 station with a clear differentiation of the large tide from the small tide $(20-30 \mathrm{~cm})$ in the 624 period of neap tide. The results indicated that utilizing an undersea tunnel for 625 muography offers a practical solution for tide measurements in important locations such 626 as near heavy maritime traffic waterlines where the conventional tide monitoring is 627 difficult. Moreover, undersea muography will offer an alternative solution to monitor 628 the sedimentation process on the shallow seafloor where acoustic methods are difficult 629 to implement. It is currently planned that UK-HKMSDD will be deployed in an 630 undersea tunnel in the UK to compare the results under the conditions of a different 631 undersea environment. We anticipate that further knowledge and experience in undersea 
632 muography will be accumulated as other HKMSDDs are installed in tunnels worldwide

633 for the application of this technique to imaging targets such as tides, natural resources

634 and the seafloor topography of coastal regions.

635

636

637 Method

638

639 Muographic sensor module. The muographic sensor module (MSM) consists of two 640 scintillation detectors, a high voltage power suply unit (HVU), and a 641 discriminator-coincidence unit (DCU). Each scintillation detector consists of a plastic 642 scintillator (ELJEN EJ-200) with dimensions of $20 \mathrm{~mm}$ in thickness, $100 \mathrm{~mm}$ in width 643 and 1500 in length that is coupled with a photomultiplier tube (PMT) (HAMAMATSU $644 \mathrm{H7195}$ ) via an acryl light guide. The HVU (Technoland Z-SYS 070HV) is a 2-channel 645 high voltage power supply that can apply a high voltage ranging 0-2000 V to 2 PMTs of 646 the MSM. A 7-segment red LED panel attached to the HVU displays the value of the 647 voltage applied to the PMTs (Figure 3B). The DCU (Technoland Z-SYS 070DC) 648 consists of a 2-channel discriminator and a coincidence circuit. When the DCU triggers 649 the signal, the attached blue LED lights up (Figure 3B). The input signals are negative 650 analogue pulses and the output signals are RS422. The input connecter type is LEMO 651 and the output connector type is D-SUB 25 PIN. The MSM's are anchored to the tunnel 652 wall with bolts and frames to fix their position.

653

654 HKMSDD segment. An HKMSDD segment consists of 10 MSMs with an interval of $65510 \mathrm{~m}$ and the data acquisition center (DAC) located at the center of the segment. Each 656 MSM is connected to DAC with the water-resist D-SUB cables (IP67). The cable 657 lengths are different, depending on the distance of MSMs from DAC, and a pair of 658 10-m, 20-m, 30-m, and 40-m cables are used. Due to the asymmetric positions of DCU 659 within the HKMSDD segment, the lengths of the cables to the first and 10th detectors 660 are different: $50 \mathrm{~m}$ and $55 \mathrm{~m}$. DAC consists of (A) four complex programmable logic 661 devices (CPLD) (Intel 10M08), (B) three green LED panels (Rohm LAP-301 ML), (C) 662 a 10-MHz temperature compensating clock (TCC) (Mita-Dempa MX033-0510-10MHz), 663 (D) switched mode power supply (SMPS) (Technoland Z-SYS 070PS), and (E) a 664 microcomputer board (Raspberry Pi 4). (A) is used for counting the number of signals 
665 output from DCU. (B) is used for displaying the number of counts. Each LED panel has 66610 8-digit, 7-segment displays. Three LED panels respectively count the number of 667 single and coincidence counts. $(\mathrm{C})$ is used for measuring the time. A heating device is 668 attached to the clock and the temperature-dependent variation is suppressed to less than $66910 \mathrm{ppm}$ for the seasonal temperature variation. (D) is used as a power supply for HVU 670 and DCU. (E) is used for sending the data to the external server. An electric cable and 671 an 8-core optical fiber cable were used for connect between DAC and the electric room 672 of the Aqua-Line to supply electric power to the HKMSDD segment and to transfer the 673 collected data including the text and video data to the external server. The network 674 speed was 1 Gbps on a best-effort basis.

675

676

\section{References}

678 1. Nicholls, R. J. et al. Sea-level rise and its possible impacts given a 'beyond $4{ }^{\circ} \mathrm{C}$ 679 world' in the twenty-first century. Philos. Trans. R. Soc. A 369, 161-181 (2011).

680

681

2. Dahl, K. A., Fitzpatrick, M. F. \& Spanger-Siegfried, E. Sea level rise drives increased 682 tidal flooding frequency at tide gauges along the U.S. East and Gulf Coasts: projections 683 for 2030 and 2045. PLOS ONE 12, e0170949 (2017).

684

685 3. Coles, S. An Introduction to Statistical Modeling of Extreme Values. Springer Verlag, 686 London (2001).

687

688 4. Strauss, B. H., Ziemlinski, R., Weiss, J. L. \& Overpeck, J. T. Tidally adjusted 689 estimates of topographic vulnerability to sea level rise and flooding for the contiguous 690 United States. Environ. Res. Lett. 7, 014033 (2012).

691

692 5. Liu, N. et al. High Spatio-Temporal Resolution Deformation Time Series With the 693 Fusion of InSAR and GNSS Data Using Spatio-Temporal Random Effect Model, IEEE 694 Trans. Geosci. Remote Sens. $\quad 57, \quad 1-17 \quad$ (2018). 695 https://doi.org10.1109/TGRS.2018.2854736

696

697 6. Wdowinski, S. Space-based detection of wetlands' surface water level changes from 
698 L-band SAR interferometry. Remote. Sens. Environ. 112, 681-696 (2008).

699

700 7. Kim, J.-W. Integrated analysis of PALSAR/Radarsat-1 InSAR and ENVISAT 701 altimeter data for mapping of absolute water level changes in Louisiana wetlands. 702 Remote Sens. Environ. 113, 2356-2365 (2009).

703

704 8. Sang-Hoon, H., Wdowinski, S., Sang-Wan, K. Evaluation of TerraSAR-X 705 Observations for Wetland InSAR Application. IEEE Trans. Geosci. Remote Sens. 48, 706 864-873 (2010).

707

708 9. Kim, S.-W. Interferometric Coherence Analysis of the Everglades Wetlands, South 709 Florida. IEEE Trans. Geosci. Remote Sens. 51, 5210-5224 (2013).

710

711 10. Wdowinski, S. Remote-sensing monitoring of tide propagation through coastal 712 wetlands. Oceanography 26, 64 (2013).

713

714 11. Lu, Z., Kwoun, O.-I. Radarsat-1 and ERS InSAR analysis over southeastern coastal 715 Louisiana: Implications for mapping water-level changes beneath swamp forests. IEEE 716 Trans. Geosci. Remote Sens. 46, 2167-2184 (2008).

717

718 12. Wild, C.T., Marsh, O.J., Rack, W. Differential interferometric synthetic aperture 719 radar for tide modelling in Antarctic ice-shelf grounding zones, The Cryosphere 13, 720 3171-3191 (2019).

721

722 13. Testut, L. The sea level at Port-aux-Français, Kerguelen Island, from 1949 to the 723 present. Ocean. Dynam. 56, 464-472 (2006).

725 14. Lourey, M. J., Dunn, J. R. \& Waring, J. A mixed-layer nutrient climatology of 726 Leeuwin Current and Western Australian shelf waters: Seasonal nutrient dynamics and 727 biomass. J. Marine. Syst. 59, 25-51 (2006).

729 15. Tanaka, H.K.M. Muometric positioning system ( $\mu$ PS) with cosmic muons as a new 730 underwater and underground positioning technique. Sci Rep 10, 18896 (2020). 

736739 (1970).

18. Morishima, K. et al. Discovery of a big void in Khufu's Pyramid by observation of cosmic-ray muons. Nature 552, 386-390 (2017).

740

19. Lesparre, N. et al. Density muon radiography of La Soufrifiere of Guadeloupe volcano: comparison with geological, electrical resistivity and gravity data. Geophys. $J$. Int. 190, 1008-1019 (2012).

20. Jourde, K. et al. Muon dynamic radiography of density changes induced by hydrothermal activity at the La Soufrière of Guadeloupe volcano. Sci. Rep. 6, 33406 747 (2016).

748

749 21. Rosas-Carbajal, M. et al. Three-dimensional density structure of la soufriére de 750 Guadeloupe lava dome from simultaneous muon radiographies and gravity data. 751 Geophys. Res. Lett. 44, 6743-6751 (2017).

753 22. Tanaka, H. K. M. et al. High resolution imaging in the inhomogeneous crust with 754 cosmic-ray muon radiography: the density structure below the volcanic crater floor of Mt. Asama, Japan. Earth Planet. Sci. Lett. 263, 104113 (2007). muons: The structure beneath Showa-Shinzan Lava Dome, Japan. Geophys. Res. Lett. 34, 053007 (2007). 
25. Tanaka, H. K. M., Kusagaya, T. \& Shinohara, H. Radiographic visualization of magma dynamics in an erupting volcano. Nat. Commun. 5, 3381 (2014).

767

26. Tanaka, H. K. M. Muographic mapping of the subsurface density structures in 769 Miura, Boso and Izu peninsulas, Japan. Sci. Rep. 5, 8305 (2015).

770

27. Tanaka, H. K. M. Instant snapshot of the internal structure of Unzen lava dome, 772 Japan with airborne muography. Sci.Rep. 6, 39741 (2016).

773

774

28. Olah, L., Tanaka, H. K. M., Ohminato, T. \& Varga, D. High-definition and 775 low-noise muography of the Sakurajima volcano with gaseous tracking detectors. Sci.

776 Rep. 8, 3207 (2018).

777

29. Tanaka, H.K.M., Sumiya, K. \& Oláh, L. Muography as a new tool to study the 779 historic earthquakes recorded in ancient burial mounds, Geosci. Instrum. Method. Data Syst. 9, 357-364, (2020). https://doi.org/10.5194/gi-9-357-2020.

781

782

30. Tanaka, H.K.M. Development of the muographic tephra deposit monitoring system.

Sci Rep 10, 14820 (2020). https://doi.org/10.1038/s41598-020-71902-1

784

31. Oláh, L. et al. CCC-based muon telescope for examination of natural caves. Geosci. 786 Instrum. Method Data Syst. 1, 229-234 (2012).

32. Tioukov, V. et al. First muography of Stromboli volcano. Sci.Rep. 9, 6695 (2019).

33. Cimmino, L., Baccani, G., Noli, P. et al. 3D Muography for the Search of Hidden

Cavities. Sci Rep 9, 2974 (2019). https://doi.org/10.1038/s41598-019-39682-5

34. Lo Presti, D., Riggi, F., Ferlito, C. et al. Muographic monitoring of the 794 volcano-tectonic evolution of Mount Etna. Sci Rep 10, 11351 (2020). 795 https://doi.org/10.1038/s41598-020-68435-y 
797 35. Thompson, L.F. et al. Muon tomography for railway tunnel imaging. Phys. Rev. Res. 798 2, 023017 (2020). https://doi.org/10.1103/PhysRevResearch.2.023017

799

800 36. Ambrosino, F. et al. Joint measurement of the atmospheric muon flux through the 801 Puy de Dôme volcano with plastic scintillators and Resistive Plate Chambers detectors. 802 J. Geophys. Res. 120, 7290-7307 (2015).

803

804 37. Saracino, G. et al. Imaging of underground cavities with cosmic-ray muons from 805 observations at Mt. Echia (Naples). Sci.Rep. 7, 1181 (2017).

806

807 38. Roberts, A. The birth of high-energy neutrino astronomy: A personal history of the 808 DUMAND project. Rev. Mod. Phys. 64, 259-312 (1992).

809

810

39. Ageron, M, et al. ANTARES: the first undersea neutrino telescope. Nucl. Instrum.

811

Meth. A 656, 11-38 (2012). .

812

813

40. KM3NeT Collaboration. KM3NeT-Technical Design Report (2010). Retrieved from 814 http://km3net.phys.uoa.gr/KM3NeT-TDR.pdf

815

816

41. KM3NeT Collaboration. Letter of Intent for KM3NeT 2.0 (2016). Retrieved from https://www.km3net.org/letter-of-intent-for-km3net-2-0-2/

818

42. Ageron, M., Aiello, S., Ameli, F. et al. Dependence of atmospheric muon flux on 820 seawater depth measured with the first KM3NeT detection units. Eur. Phys. J. C 80, 99 821 (2020). https://doi.org/10.1140/epjc/s10052-020-7629-z

823 43. Japan Coast Guard. Chiba real time tide gauge data (2021). Retrieved from 824 https://www1.kaiho.mlit.go.jp/TIDE/gauge/gauge.php?s=0053

826 44. Tilav, S. et al. Atmospheric variation as observed by IceCube (2010). Retrieved 827 from https://arxiv.org/abs/1001.0776

829 45. Japan Meteorological Agency. Past Meteorological Data (2021). Retrieved from 
830 https://www.data.jma.go.jp/obd/stats/etrn/index.php?prec_no=44\&block_no=47662\&ye

831 ar=\&month $=\&$ day $=\&$ view $=$

832

833 46. Daya Bay Collaboration. Seasonal variation of the underground cosmic muon flux

834 observed at Daya Bay, J. Cosmol. and Astropart. Phys. 2018, 001 (2018).

835 https://doi.org/10.1088/1475-7516/2018/01/001

836

837 47. Borexino Collaboration. Modulations of the cosmic muon signal in ten years of

838 Borexino data, J. Cosmol. and Astropart. Phys. 2019, 046 (2019).

839 https://doi.org/10.1088/1475-7516/2019/02/046

840

841 48. Snodgrass, F. E. et al. Propagation of ocean swell across the Pacific. Philos. Trans.

842 R. Soc. London, Ser. A 249, 431- 497 (1966).

843

844 49. AECOM. Extreme Storms in San Francisco Bay -Past to Present Final Report

845 (2016). Retrieved from

846 http://www.adaptingtorisingtides.org/wp-content/uploads/2016/05/Extreme_Storms_SF

847 _Bay_Past_to_Present_FINAL.pdf

848

849 50. Ministry of Land, Infrastructure, Transport and Tourism. Report of Typhoon 15

850 (2019). Retrieved from https://www.mlit.go.jp/common/001314446.pdf

851

852 51. Rascle, N. et al. A global wave parameter database for geophysical applications.

853 Part 1: Wave-current-turbulence interaction parameters for the open ocean based on

854 traditional parameterizations, Ocean Modell. 25, 154-171 (2008),

855 https://doi.org/10.1016/j.ocemod.2008.07.006 .

856

857 52. Guo, X. \& Yanagi, T. Three-dimensional structure of tidal current in the East China

858 Sea and the Yellow Sea. J. Oceanogr. 54, 651-668 (1998).

859

860 53. Ji, Z.G. et al. Three-dimensionalmodeling of hydrodynamic processes in the St.

861 Lucie Estuary. Estuar. Coast. Shelf Sci.73, 188-200 (2007). 
863 54. Stanev, E.V. Understanding Black Sea dynamics: overview of recent numerical 864 modelling. Oceanography 18, 56-75 (2005).

865

866

55. Lermusiaux, P.F.J. Evolving the subspace of the three-dimensional multiscale ocean 867 variability: Massachusetts Bay, J. Mar. Syst. 29, 385-422 (2001).

868

869

870

56. Gao, X \& Yanagi T. Three Dimensional Structure of Tidal Currents in Tokyo Bay, 871

872 Japan, Lamer 32, 173-185 (1994).

873

57. Matsumoto, K. et al. GOTIC2: A Program for Computation of Oceanic Tidal 874

875

58. ten Brink , U.S. et al. Assessment of tsunami hazard to the U.S. East Coast using 876 relationships between submarine landslides and earthquakes, Mar. Geol. 264, 65-73 877 (2009).

878

879

59. Dixon, T.H. et al. Earthquake and tsunami forecasts: Relation of slow slip events to 880 subsequent earthquake rupture, Proc. Natl. Acad. Sci. U.S.A. 111, 17039-17044 (2014).

881

882

60. Fritz, H.M., Hillaire, J.V., Molière, E. et al. Twin Tsunamis Triggered by the 12 883 January 2010 Haiti Earthquake. Pure Appl. Geophys. 170, 1463-1474 (2013). 884 https://doi.org/10.1007/s00024-012-0479-3

885

886

61. Rosetto, T., et al. Physical modelling of tsunami using a new pneumatic wave 887 generator, Coast. Eng. 58, 517-527 (2011).

888

889

62. Naoi, M., Sato, K., Tanaka, Y. et al. Natural hazard information and migration 890 across cities: evidence from the anticipated Nankai Trough earthquake. Popul. Environ.

891 41, 452-479 (2020). https://doi.org/10.1007/s11111-020-00346-6

892

893 63. Tokyo Metropolis. Disaster Prevention Information (2013). retrieved from 894 https://www.bousai.metro.tokyo.lg.jp/taisaku/torikumi/1000902/1000402.html 
896 64. Brunn P. et al. Dredging and offshore transport of materials. J. Coast. Res. 2, 897 453-525 (2005).

898

899 65. Hodgkin, E. P. \& Hesp, P. Estuaries to salt lakes: Holocene transformation of the 900 estuarine ecosystems of south-western Australia. Aust. J. Mar. Freshw. Res. 49, 183901201 (1998).

902

903 66. Chenhall, B.E. et al. Anthropogenic marker evidence for accelerated sedimentation 904 in Lake Illawarra, New South Wales, Australia. Environ. Geol. 26, 124-135 (1995).

905

906 67. McLaughlin, L.C. Shaping Sydney Harbour: sedimentation, dredging and 907 reclamation 1788 - 1990s. Aust. Geogr. 31, 183-208 (2000).

908

909 68. Hancock, G. J. and Hunter, J. R. Use of excess 210Pb and 228Th to estimate rates of 910 sediment accumulation and bioturbation in Port Phillip Bay, Australia. Aust. J. Mar. 911 Freshw. Res. 50, 533- 545 (1999).

912

913 69. Yamashiro, M. et al. Study on characteristics of depth changing in Kanmon 914 waterway based on sounding data. J. JSCE 69, 634-639 (2013).

915

916 70. Berne, S. et al. Internal structure of subtidal sand waves revealed by high-resolution 917 seismic reflection. Sedimentology 35, 5-20 (1988).

918

919 71. Raynaud, J.-Y. et al. The offshore Quaternary sediment bodies of the English 920 Channel and its Western Approaches, J. Quat. Sci. 18, 361-371 (2003). 921

922 72. Radic, V.\& Hock, R. Regionally differentiated contribution of mountain glaciers 923 and ice caps to future sea-level rise. Nat. Geosci. 4, 91-94 (2011).

924

925 73. McNabb, R. W. \& Hock, R. Alaska tidewater glacier terminus positions, 1948-2012. 926 J. Geophys. Res. Earth Surf. 119, 153-167 (2014).

927

928 74. Brinkerhoff, D., Truffer, M. \& Aschwanden, A. Sediment transport drives tidewater 
929 glacier periodicity. Nat Commun 8, 90 (2017). https://doi.org/10.1038/s41467-017-

$930 \quad 00095-5$

931

932 75. Charles R. Warren et al. Glaciar Upsala, Patagonia: rapid calving retreat in fresh 933 water, Ann. Glaciol. 21, 311 - 316 (1995). https://doi.org/10.3189/S0260305500015998

934

935 76. Bell, R.E., Banwell, A.F., Trusel, L.D. et al. Antarctic surface hydrology and 936 impacts on ice-sheet mass balance. Nat. Clim. Change. 8, 1044-1052 (2018). 937 https://doi.org/10.1038/s41558-018-0326-3

938

939 77. Meier, M. F. Contribution of small glaciers to global sea level. Science 226, 1418$9401421(1984)$.

941

942 78. Stuart-Smith, R.F., Roe, G.H., Li, S. et al. Increased outburst flood hazard from

943 Lake Palcacocha due to human-induced glacier retreat. Nat. Geosci. 14, 85-90 (2021).

944 https://doi.org/10.1038/s41561-021-00686-4

945

946 79. Delcroix, T., Cravatte, S. \& McPhaden, M. J. Decadal variations and trends in 947 tropical Pacific sea surface salinity since 1970. J. Geophys. Res. 112, 266-281 (2007).

948

949 80. Durack, P. J., Wijffels, S. E. \& Matear, R. J. Ocean salinities reveal strong global 950 water cycle intensification during 1950 to 2000. Science 336, 455-458, 951 https://doi.org/10.1126/science.1212222 (2012).

952

953 81. Zeng, L. et al. Decadal variation and trends in subsurface salinity from 1960 to 2012 954 in the northern South China Sea. Geophys. Res. Lett. 43, 12181-12189 (2016).

956 82. Zeng, L., Chassignet., E. P., Schmitt., R. W., Xu., X. \& Wang, D. Salinification in 957 the South China Sea since late 2012: A reversal of the freshening since the 1990s. 958 Geophys. Res. Lett. 45, 2744-2751 (2018). https://doi.org/10.1002/2017GL076574 959

96083 Abdullah, T., Romshoo, S.A. \& Rashid, I. The satellite observed glacier mass 961 changes over the Upper Indus Basin during 2000-2012. Sci. Rep. 10, 14285 (2020). 
962

963

964

965

966

967

968

969

970

971

972

973

974

975

976

977

978

979

980

981

982

983

984

985

986

987

988

989

990

991

992

993

91

994 92. Dieng, H. B., Cazenave, A., Meyssignac, B. \& Ablain, M. New estimate of the

https://doi.org/10.1038/s41598-020-71281-7

84 Tak, S. \& Keshari, A.K. Investigating mass balance of Parvati glacier in Himalaya using satellite imagery based model. Sci. Rep. 10, 12211 (2020). https://doi.org/10.1038/s41598-020-69203-8

85 Gregory, J. M. et al. The flux-anomaly-forced model intercomparison project (FAFMIP) contribution to CMIP6: Investigation of sea-level and ocean climate change in response to $\mathrm{CO} 2$ forcing. Geosci. Model Dev. 9, 3993-4017 (2016). https://doi.org/10.5194/gmd-9-3993-2016.

86. Antonov, J. I., Levitus, S. \& Boyer, T. P. Steric sea level variations during 19571994: Importance of salinity. J. Geophys. Res. 107, 8013 (2002).

https://doi.org/10.1029/2001JC000964

87. Munk, W. Ocean freshening, sea level rising. Science 300, 2041-2043 (2003).

88. Wadhams, P. \& Munk, W. Ocean freshening, sea level rising, sea ice melting. Geophys. Res. Lett. 31, L11311 (2004).

89. Dangendorf, S. et al. Reassessment of 20th century global mean sea level rise. Proc. Natl. Acad. Sci. U.S.A. 114, 5946-5951, https://doi.org/10.1073/pnas.1616007114 (2017).

90. Rhein, M. et al. Observations: Ocean. In: Climate Change 2013: The Physical Science Basis. Contribution of Working Group I to the Fifth Assessment Report of the Intergovernmental Panel on Climate Change Stocker, T. F. et al. (eds). Cambridge University Press, Cambridge, United Kingdom and New York, NY, USA (2013).

91. Watson, C. S. et al. Unabated global mean sea-level rise over the satellite altimeter era. Nat. Clim. Change. 5, 565-568 (2015). https://doi.org/10.1038/nclimate2635 
995 current rate of sea level rise from a sea level budget approach. Geophys. Res. Lett. 44,

996 3744-3751 (2017). https://doi.org/10.1002/2017GL073308

997

998

999 Acknowledgements

1000 This project was supported by the East Nippon Expressway Company Limited, the

1001 Geospatial Information Authority of Japan, the Ministry of Land, Infrastructure,

1002 Transport and Tourism, Ministry of Education, Culture, Sports, Science and

1003 Technology, and the Japan Society for the Promotion of Science. Fruitful discussions

1004 with the Japan Coast Guard are also acknowledged.

1005

1006 Author Information

1007 Consortium

1008 MAGMA-HKMSDD Collaboration

1009 1. University of Tokyo, Japan

1010 Hiroyuki K.M. Tanaka

1011 Jun Matsushima

1012 Yusuke Yokota

1013 László Oláh,

1014 Naoto Hayashi,

1015 Hiroyuki Takahashi

1016 Hirohisa Mori

1017 Kenji Shimazoe

1018 Hideaki Miyamoto

1019 Eriko Maeda

1020 Shouhei Hanaoka

1021 Yukihiro Nomura

1022 Takeharu Yoshikawa

1023 Yoshihiro Nishiaki

1024 Yasuhiro Kato

1025 Masaki Satoh

1026 Masaatsu Aichi

1027 
1028 2. The University of Salerno, Salerno

1029 Cristiano Bozza

1030

1031 3. Istituto Nazionale di Fisica Nucleare - Laboratori Nazionali del Sud

1032 Rosa Coniglione

1033 Danilo L. Bonanno

1034

1035 4. Durham University, UK

1036 Jon Gluyas

1037

1038 5. Kerttu Saalasti Institute, University of Oulu, Finland

1039 Marko Holma

1040

1041 6. Muon Solutions Oy Ltd, Finland

1042 Marko Holma

1043 Pasi Kuusiniemi

1044

1045 7. Arctic Planetary Science Institute

1046 Marko Holma

1047 Pasi Kuusiniemi

1048

1049 8. NEC Corporation, Tokyo, Japan

1050 Shin-ichi Miyamoto

1051 Norimasa Kumagai

1052 Kazuhiro Miyazawa

1053 Yoshio Ishizawa

1054 Ryuta Asami

1055 Osamu Kamoshida

1056 Toru Takeno

1057 Tetsu Oosaki

1058

1059 9. Kyushu University, Japan

1060 Tadahiro Kin 
1061 Naoya Okamoto

1062

1063 10. The University of Atacama, Chile

1064 Giovanni Leone

1065

1066 11. The University of Catania, Catania, Italy

1067 Domenico Lo Presti

1068 Giuseppe Gallo

1069 Franco Riggi

1070 Paola La Rocca.

1071 Carmelo Ferlito

1072

1073 12. Istituto Nazionale di Fisica Nucleare, Catania, Italy.

1074 Domenico Lo Presti

1075 Franco Riggi

1076 Paola La Rocca.

1077 Danilo L. Bonanno

1078

1079 13. Kansai University, Osaka, Japan

1080 Takefumi Hayashi

1081 Kenji Sumiya

1082

1083 14. The University of Sheffield, UK

1084 Lee F. Thompson

1085 Patrick Stowell

1086 Samuel J Fargher

1087

1088 15. Geoptic Ltd., UK

1089 Chris Steer

1090 Jon Gluyas

1091 Lee F. Thompson

1092 Patrick Stowell

1093 
1095 16. Boulby Underground Laboratory, UK

1096 Sean Palling

1097 Paul Scovell

1098 Christopher Toth

1099

1100 17. Wigner Research Centre for Physics, Hungary

1101 Dezső Varga,

1102 Gábor Galgóczi,

1103 Ádám L. Gera,

1104 Gergó Hamar,

1105 Szabolcs J. Balogh,

1106 Gábor Nyitrai

1107

1108 18. International Virtual Muography Institute (VMI)

1109 Hiroyuki K.M. Tanaka

1110 Jun Matsushima

1111 Kenji Sumiya

1112 László Oláh,

1113 Hirohisa Mori

1114 Tadahiro Kin

1115 Shin-ichi Miyamoto

1116 Osamu Kamoshida

1117 Takefumi Hayashi

1118 Kenji Sumiya

1119 Hiroshi Nakajima

1120 Sara Steigerwald

1121 Lee Thompson

1122 Jon Gluyas

1123 Dezső Varga,

1124 Gábor Galgóczi,

1125 Ádám L. Gera,

1126 Gergő Hamar, 
1127 Szabolcs J. Balogh,

1128 Gábor Nyitrai

1129 Domenico Lo Presti

1130 Giuseppe Gallo

1131 Cristiano Bozza

1132 Giovanni Leone

1133 Marko Holma

1134 Pasi Kuusiniemi

1135 Andrea Gimmanco

1136 Michael Tytgat

1137

1138 19. Central Research Institute of Electric Power Industry, Chiba, Japan

1139 Kimio Miyakawa

1140 Hiroshi Suenaga

1141

1142 20. JGI, Inc., Tokyo, Japan

1143 Susumu Abe

1144 Nobuo Kawai

1145 Masazumi Onishi

1146 Eiichi Asakawa

1147 Takashi Imazumi

1148 Shinji Kawasaki

1149 Ikuro Mizukoshi

1150

1151 21. Japan Petroleum Exploration Co., Ltd., Tokyo, Japan

1152 Ken'ichi Akama

1153 Koji Kashihara

1154 Takao Nibe

1155 Takeshi Shibata

1156 Katsumi Takai

1157

1158 22. Kawasaki Geological Engineering, Tokyo, Japan

1159 Aya Kamimura 
1160 Osamu Fujimoto

1161 Sunao Kanazawa

1162 Yuki Kobayashi

1163 Eiichiro Nishiyama

1164 Jun Ando

1165 Taro Kusagaya

1166 Takehiro Ohara

1167 Takeshi Ohmura

1168 Hiroshi Ohnuma

1169 Daisuke Shimokawa

1170 Keiichi Suzuki

1171 Akiko Ishii

1172 Shingo Sugimoto

1173

1174 23. Istituto Nazionale di Astrofisica, Osservatorio di Catania, Catania, Italy

1175 Giovanni Bonanno

1176 Giuseppe Romeo

1177

1178 24. Dipartimento di Ingegneria e Geologia (INGEO), Università d'Annunzio, Italy

1179 Piero D'Incecco

1180

1181 25. Istituto Nazionale di Geofisica e Vulcanologia, Catania, Italy.

1182 Carmelo Ferlito

1183

1184 26. Tokyo Metropolitan University, Tokyo, Japan

1185 Yoshiya Oda

1186

1187 27. Ghent University, Belguium

1188 Michael Tytgat

1189

1190 28. UCLouvin, Belgium

1191 Andrea Giammanco

1192 
1193 29. Nagoya University

1194 Hiroshi Ichihara

1195 Toshiki Watanabe

1196 Koshun Yamaoka

1197

1198 30. GEOSYS, Inc., Tokyo, Japan

1199 Toshio Iizuka

1200 Taro Koike

1201 Tsukasa Nishiki

1202 Katsuya Noda

1203 Nobuyuki Shimizu

1204 Kenichi Watanabe

1205

1206 31. Waseda University, Tokyo, Japan

1207 Kazuo Kamura

1208 Takumi Ueda

1209

1210 32. National Agriculture and Food Research Organization, Ibaraki, Japan

1211 Seiichiro Kuroda

1212

1213 33. National Institute of Advanced Industrial Science and Technology, Ibaraki, Japan

1214 Toshiyuki Yokota

1215

1216 34. Kyoto University, Kyoto, Japan

1217 Yuzo Ohnishi

1218

1219

\section{Contributions}

1221 HKMT, MH, PK, RC and GL wrote the text. HKMT prepared the figures. All authors 1222 reviewed the manuscript.

1223

\section{Corresponding author}

1225 Corresponding to Hiroyuki K.M. Tanaka 
1226

1227 Ethics declarations

1228 Competing interests

1229 The authors declare no competing interests.

1230

1231 


\section{Figures}

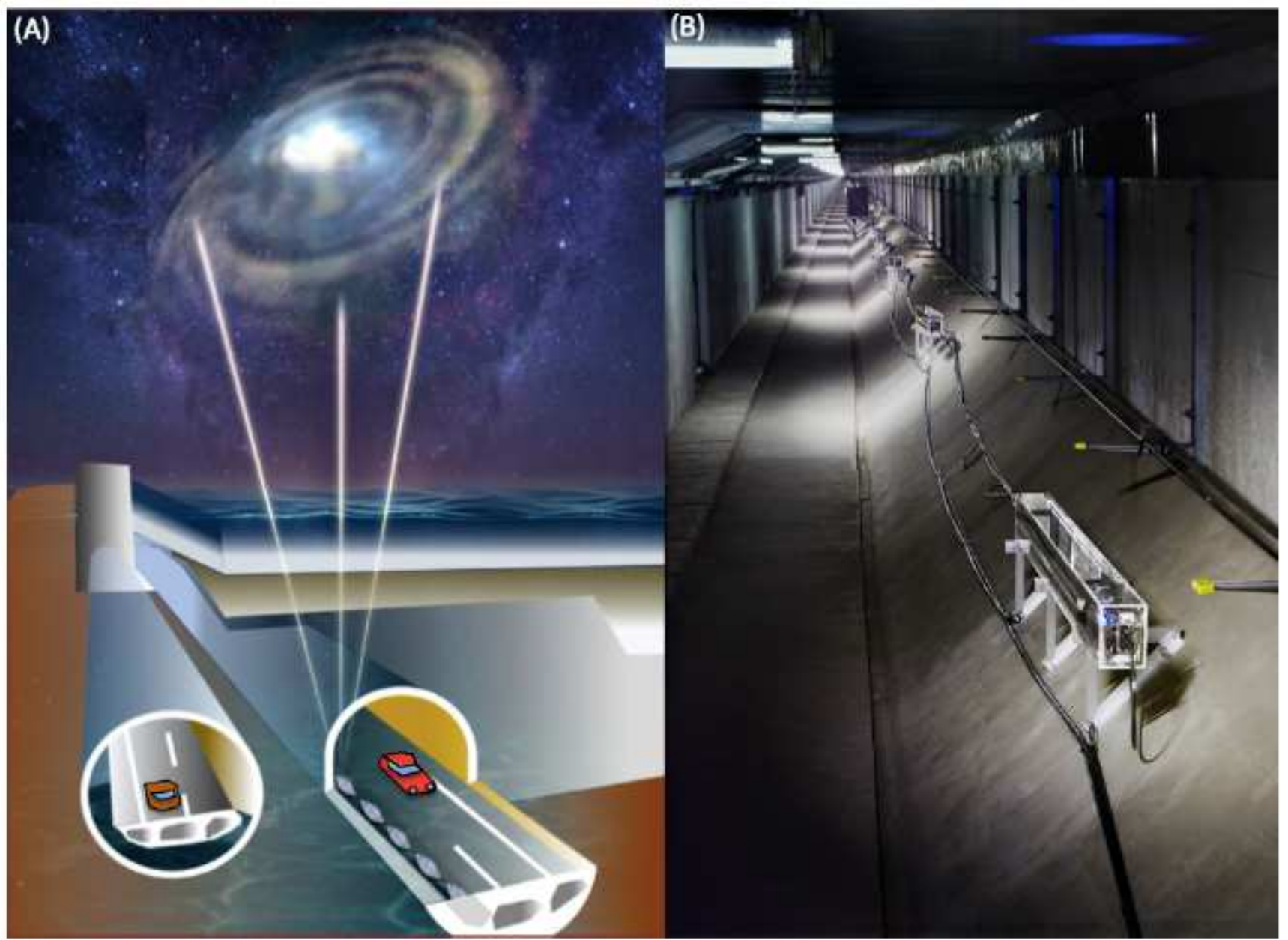

\section{Figure 1}

Conceptual view of the Tokyo-bay Seafloor Hyper-Kilometric Submarine Deep Detector (TS-HKMSDD) deployed underneath the Tokyo bay seafloor (A) and the photograph (B). HKMT drew this image and holds the copyright. HKMT holds the copyright of the photograph. 
(A)
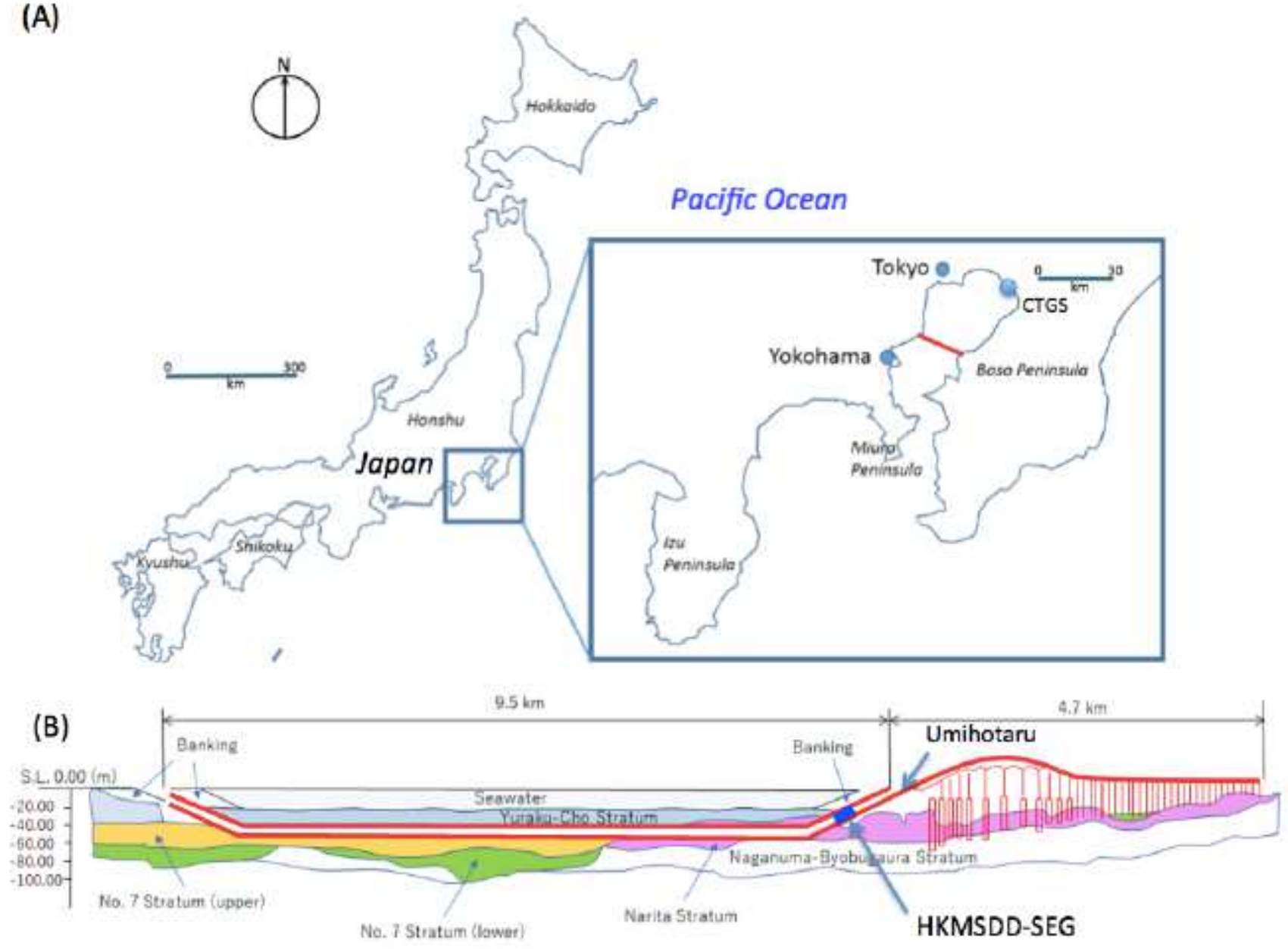

Figure 2

Location of the Tokyo Bay Aqua-Line (TBAL) in Japan (red lines) (A) and the cross-sectional view of the tunnel section (Aqua-tunnel) of TBAL (B). The symbols CTGS and HKMSDD-SEG respectively indicate the locations of the Chiba tide gauge station and the HKMSDD segment. The name Umihotaru indicates the service area that marks the transition between the bridge and tunnel part. HKMT drew the map and the image with the Microsoft PowerPoint software and holds the copyright. Note: The designations employed and the presentation of the material on this map do not imply the expression of any opinion whatsoever on the part of Research Square concerning the legal status of any country, territory, city or area or of its authorities, or concerning the delimitation of its frontiers or boundaries. This map has been provided by the authors. 
(A)

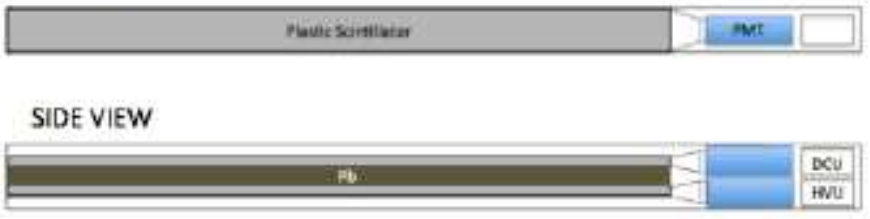

(B)

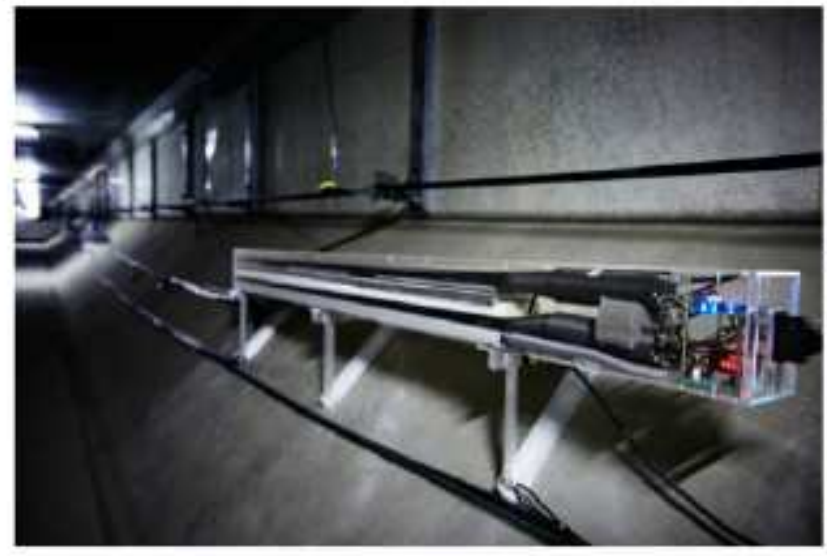

(E)

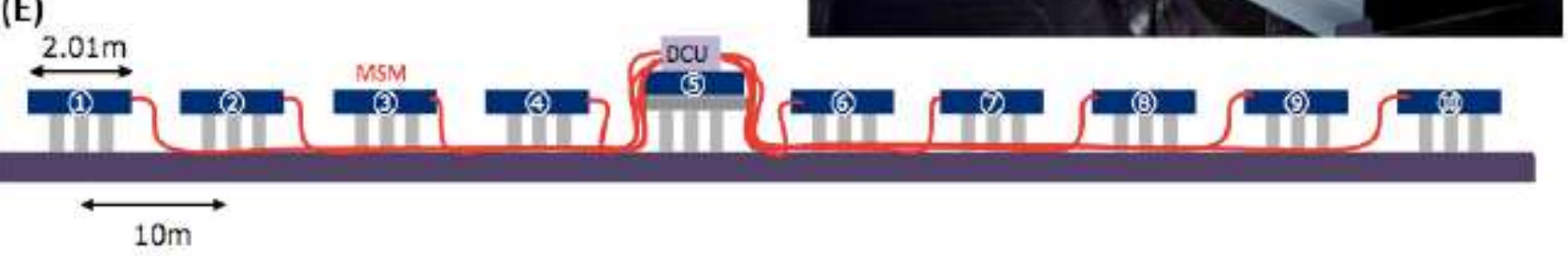

\section{(D)}
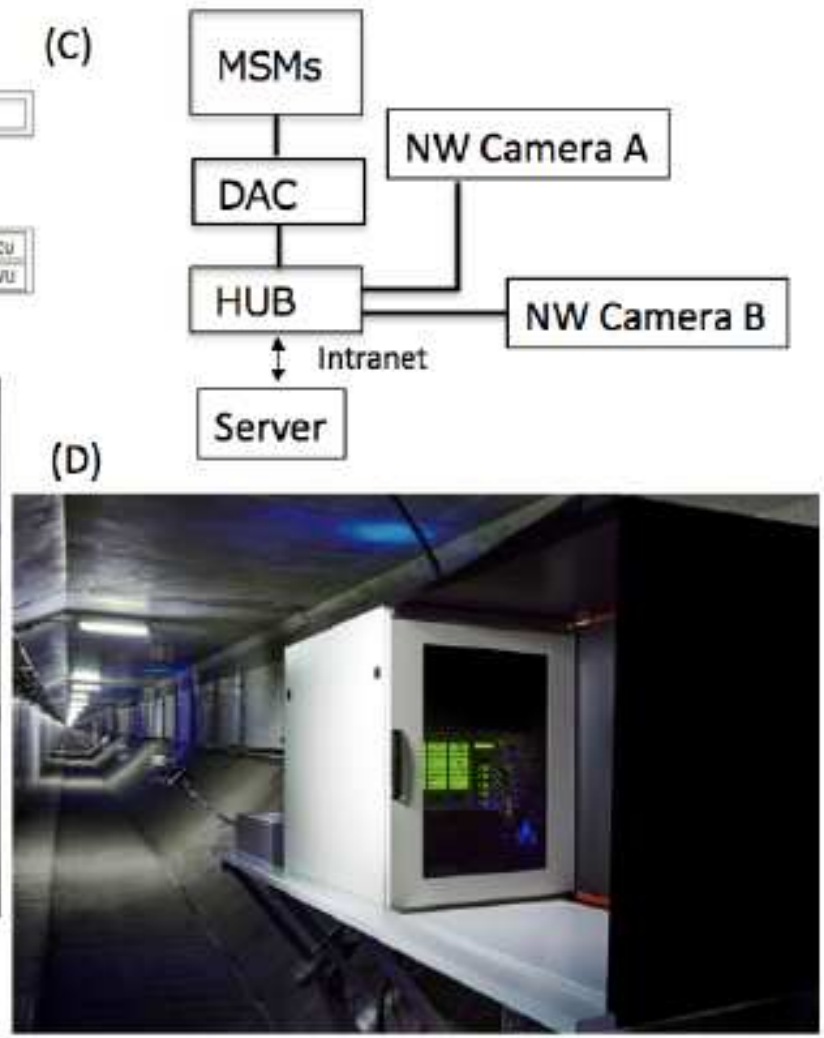

\section{Figure 3}

Configuration of the HKMSDD segment. The schematic of the muographic sensor module (MSM) (A) is shown along with a photograph of the MSM (B). The abbreviations DCU and HVU respectively indicate the discriminator-coincidence unit and the high-voltage power supply unit. The block diagram of the data collection scheme (C) is shown along with a photograph of the Data Acquisition Center (DAC) (D). The network cameras (NW Cameras) are respectively used for monitoring the MSM LEDs and the DAC 7segment LEDs. The HKMSDD server hosts a closed network. The schematic view of the HKMSDD segment is also shown (E). HKMT holds the copyright of the photographs. 


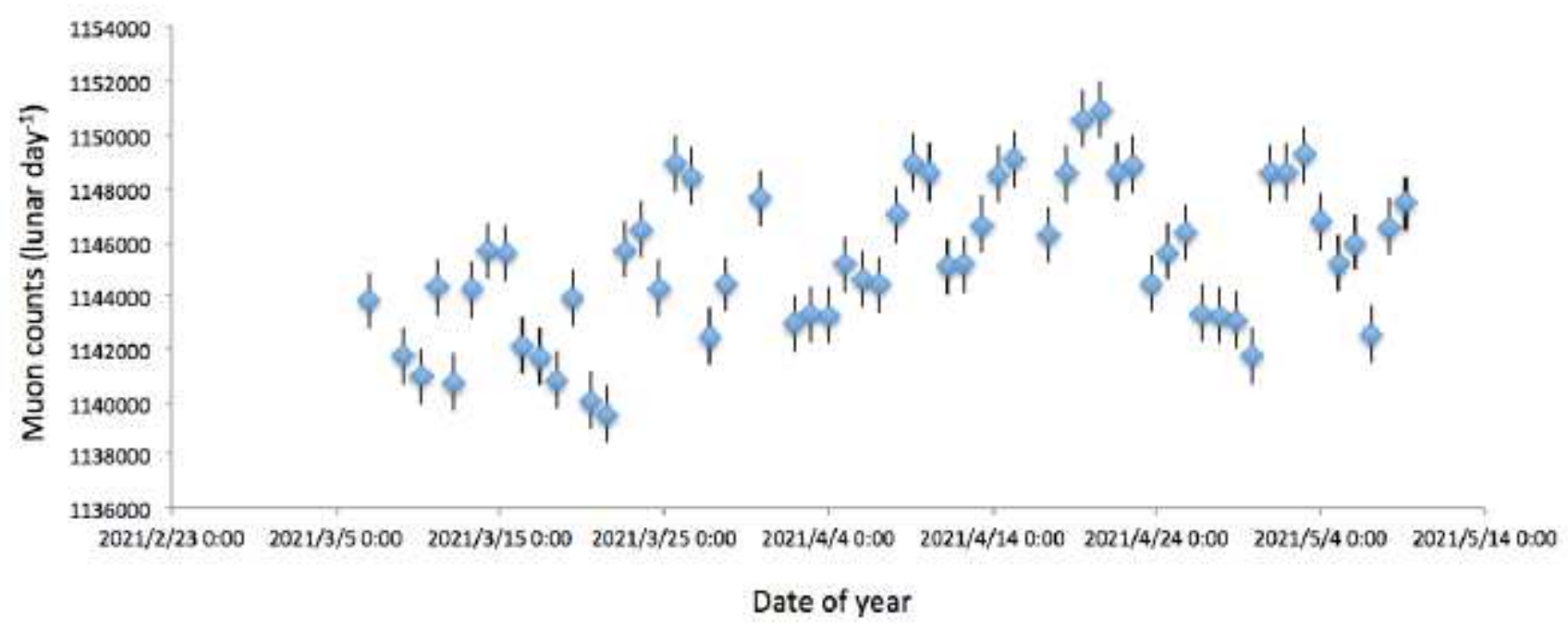

\section{Figure 4}

Time-sequential plot of the lunar-daily muon counts.
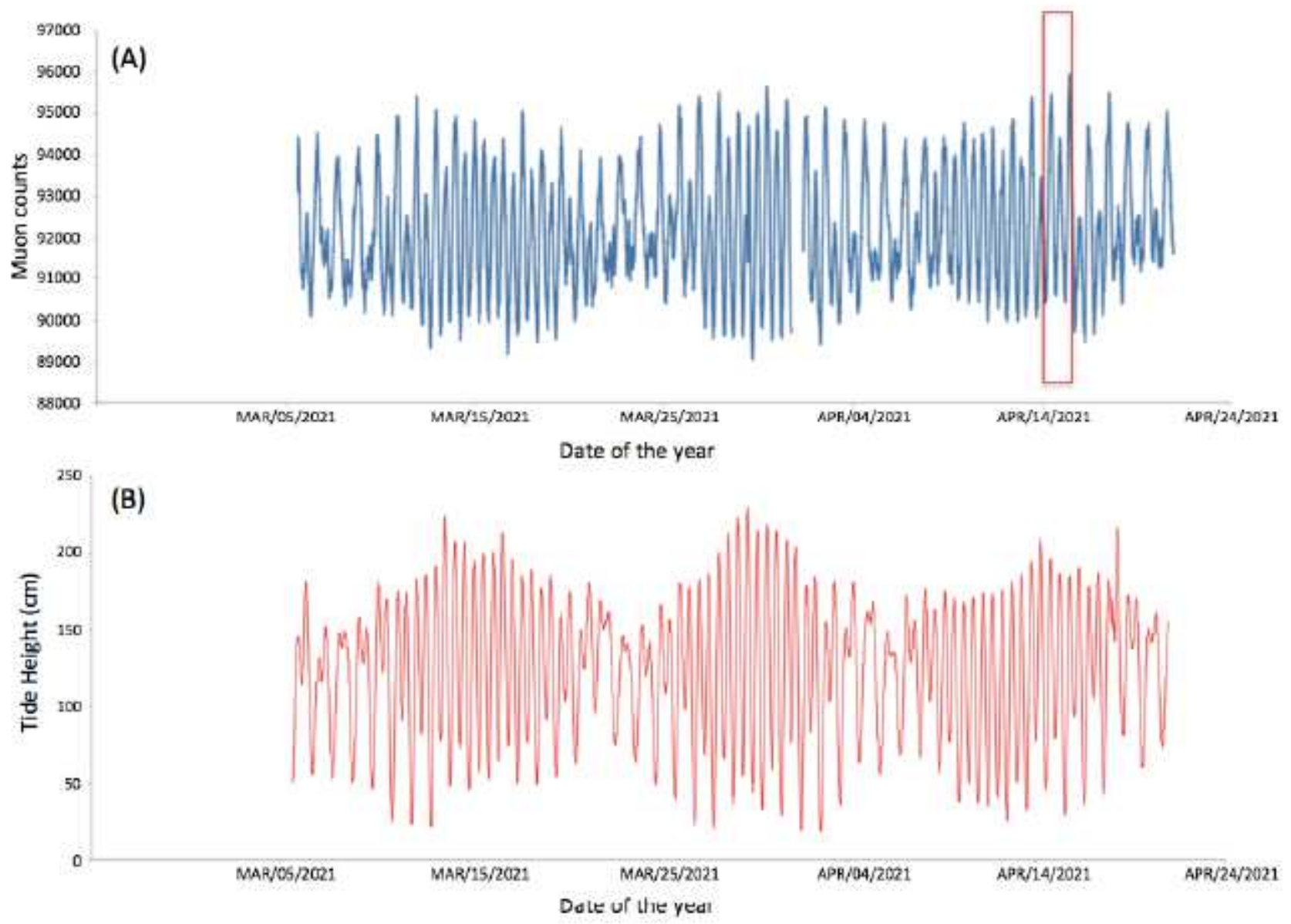

Figure 5 
Time-sequential plot of the number of muon counts collected every 5 minutes $(A)$ and the tide gauging results measured at the Chiba Tide Gauging Station (B)43. The red box indicates the period we used for the detailed analysis in Figures 6 and 8.

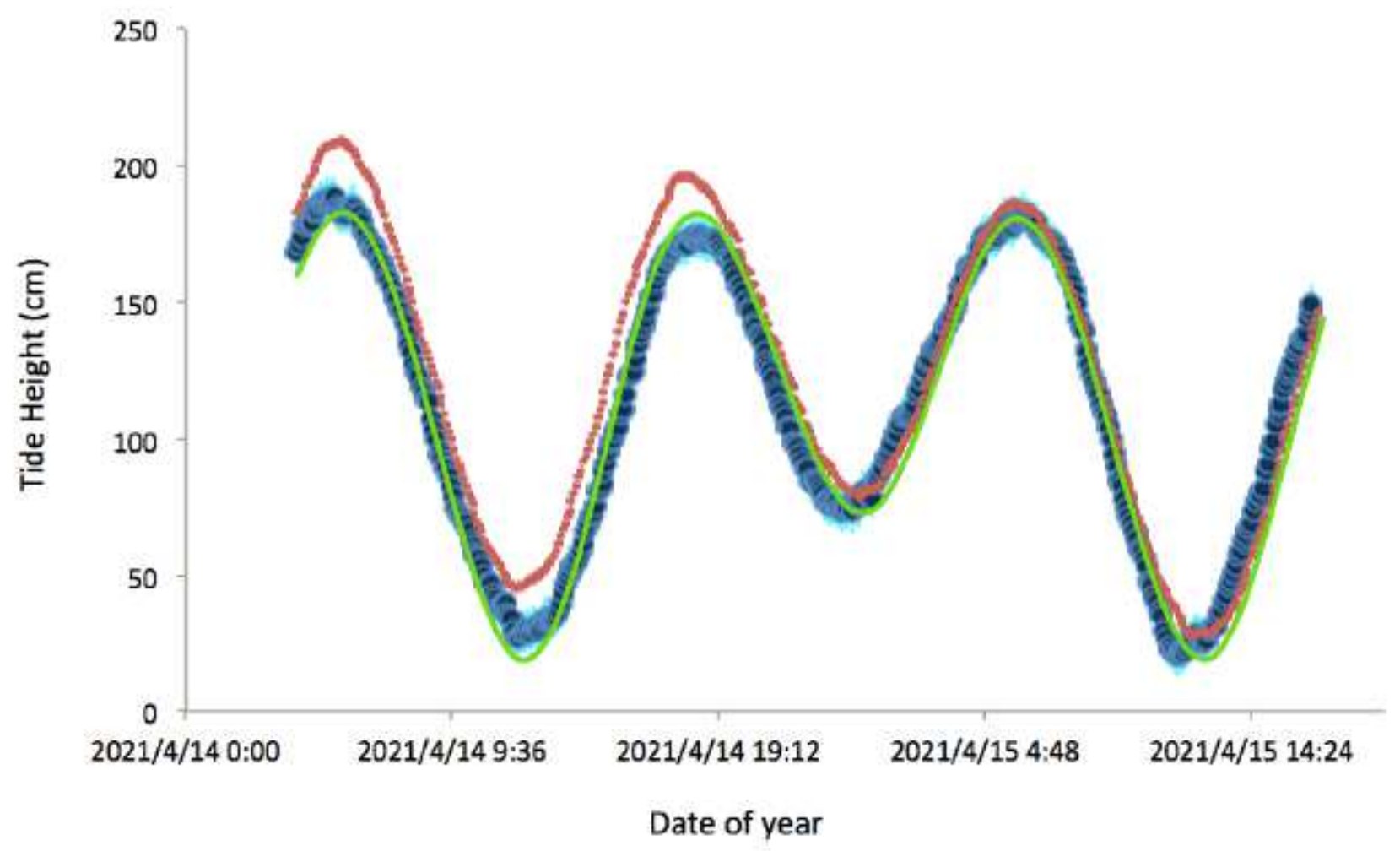

Figure 6

Tide levels converted from the muon counts. The data points (dark blue filled circles) are shown along with the statistic error bars (1 standard deviation) (sky blue lines). The tide gauging results measured at CTGS (red filled circles) and the theoretical calculation results of the astronomical tide levels (green line) are also shown (43). 


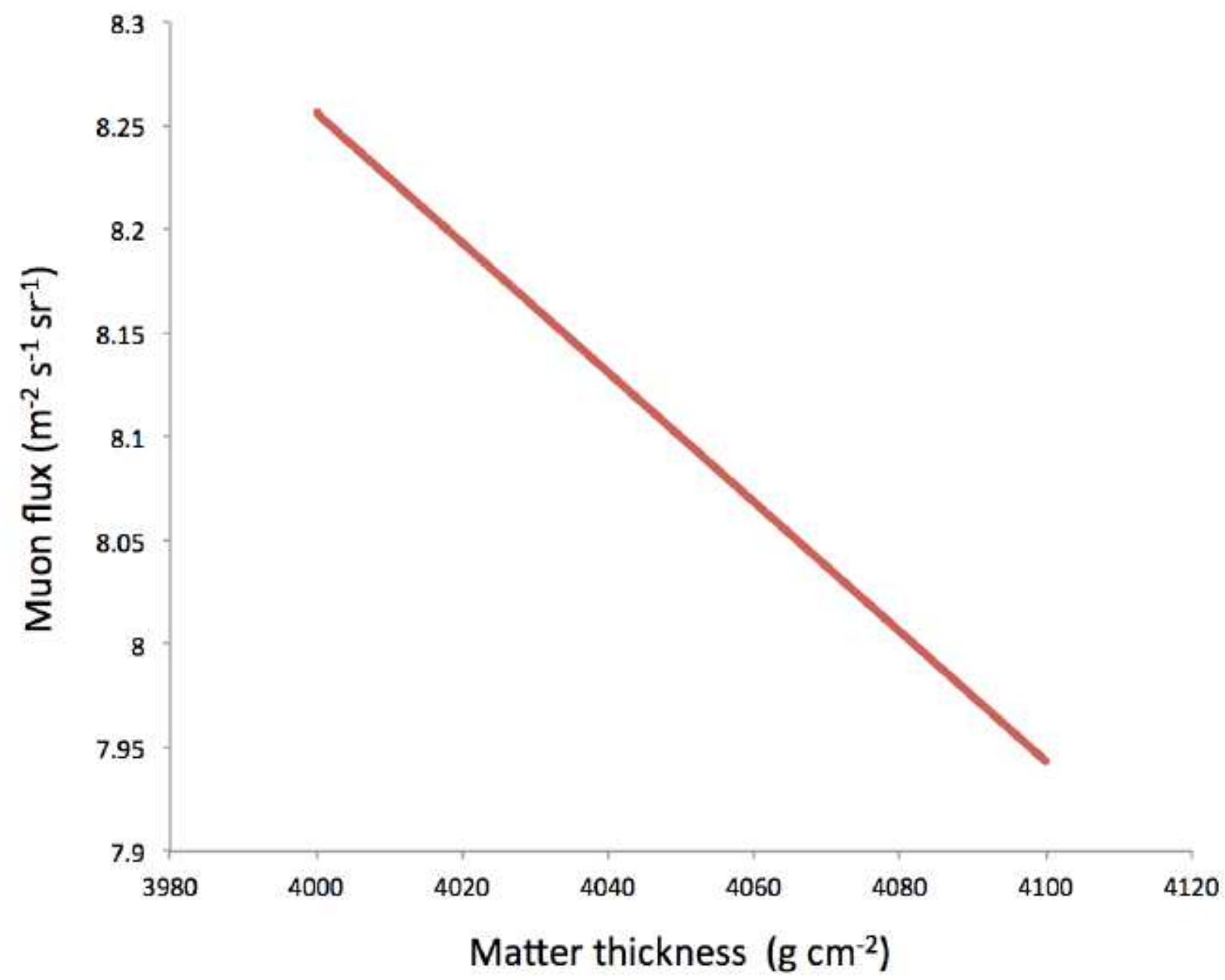

Figure 7

Muon flux expected at the Hyper-Kilometric Submarine Deep Detector (HKMSDD) segment placed within the region 500-600 $\mathrm{m}$ from Umihotaru (SEG1) for various matter thicknesses. 

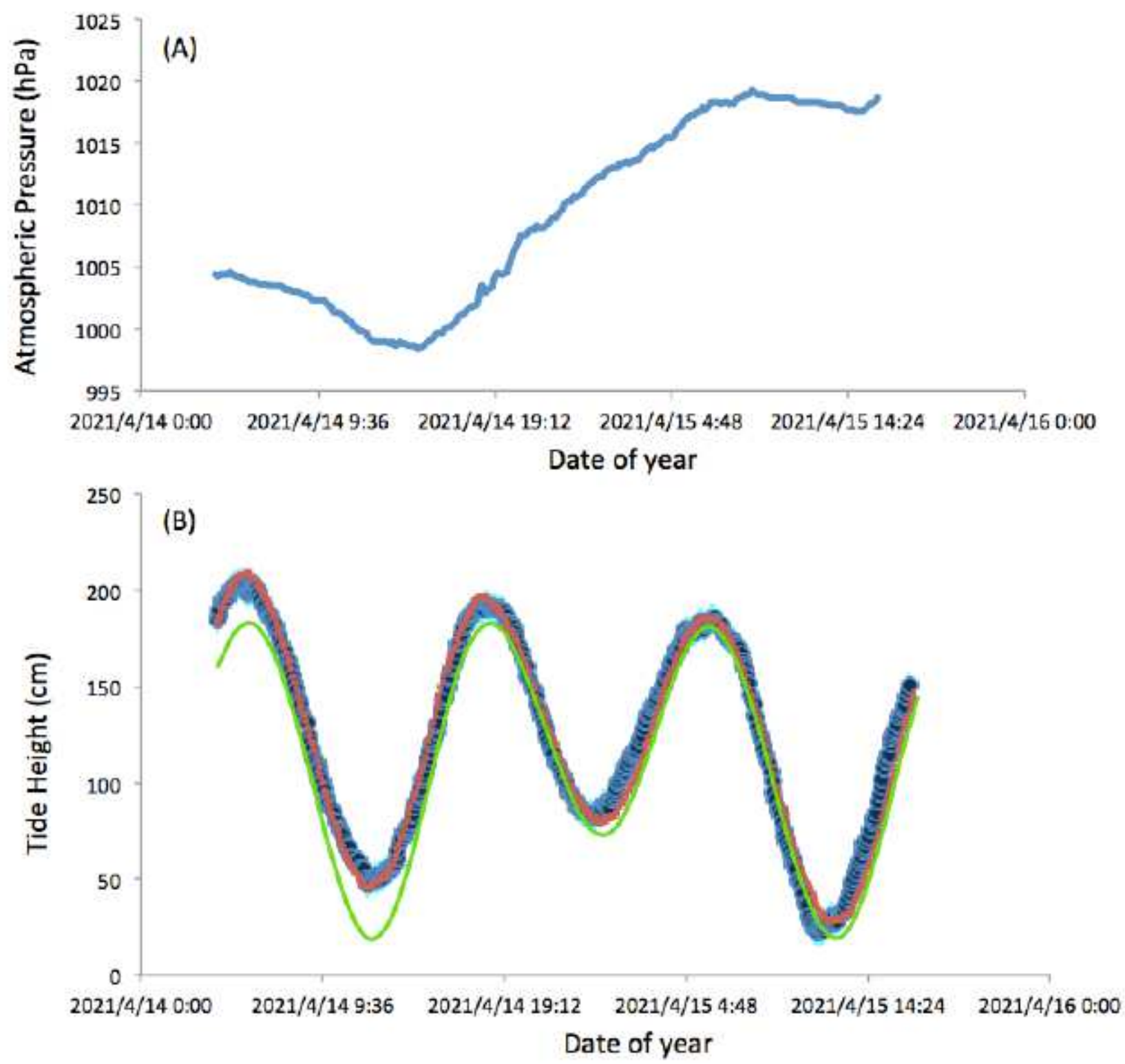

Figure 8

Hourly barometric variations measured in Tokyo, Japan (A). The values were converted to those at sea level. Tide levels converted from the muon counts with the barometric corrections. The data points (dark blue filled circles) are shown along with the statistic error bars (1 standard deviation) (sky blue line). The tide gauging results measured at CTGS (red filled circles) and the theoretical calculation results of the astronomical tide levels (green line) are also shown43. 
(A)

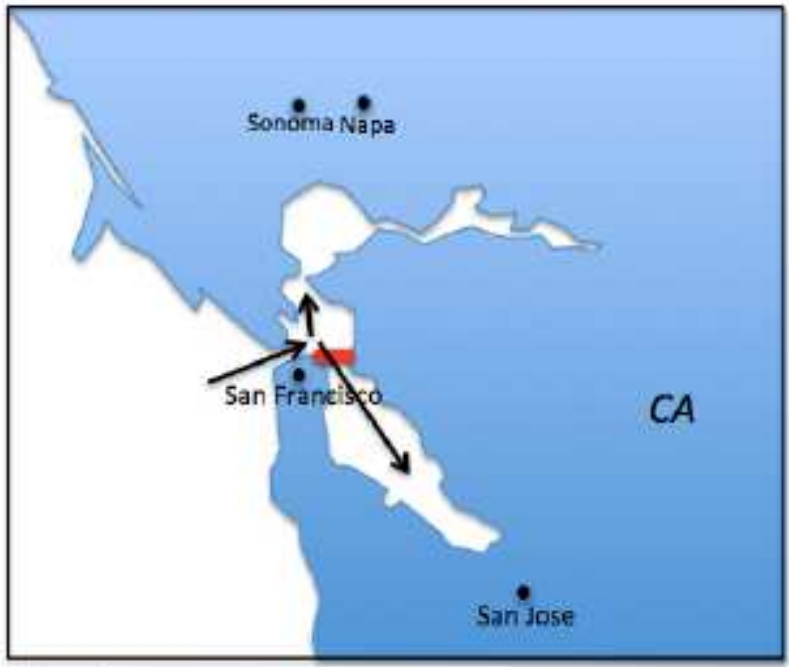

(B)

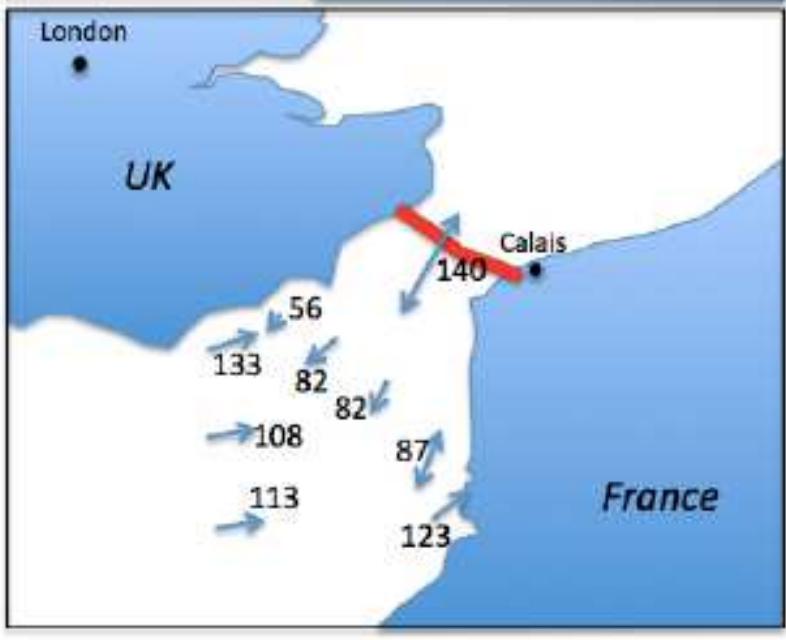

(C)

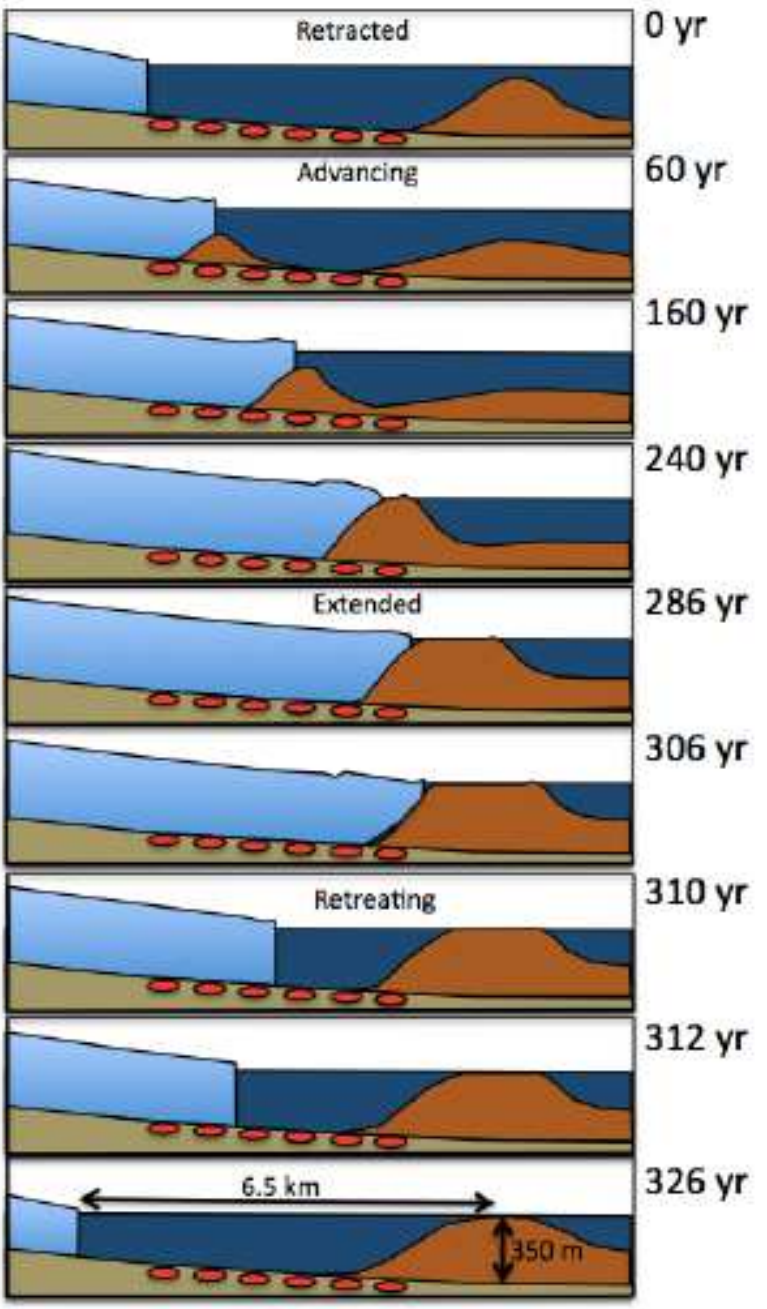

Figure 9

Possible future HKMSDD deployment sites: (A) Transbay Tube, San Francisco, CA, (B) Channel Tunnel, UK/France, and (C) Glacier Upsala, Patagonia, Chile. Red lines in (A) and (B) indicate the undersea tunnels. Black arrows in (A) indicate the direction of the pacific swells49487. Blue lines in (B) indicate the spring maximum current vectors. The numbers indicate the speed in units of $\mathrm{cm} / \mathrm{s} 66$. Red oval shape symbols in (C) indicate the hypothetical HKMSDD buried under the seafloor. HKMT drew the maps in (A) and (B) with the Microsoft PowerPoint software and holds the copyright. HKMT drew the image in (C) based on the work by Brinkerhoff et al69. Note: The designations employed and the presentation of the material on this map do not imply the expression of any opinion whatsoever on the part of Research Square concerning the legal status of any country, territory, city or area or of its authorities, or concerning the delimitation of its frontiers or boundaries. This map has been provided by the authors. 